\title{
Genome and transcriptome-based characterization of high energy carbon-ion beam irradiation induced delayed flower senescence mutant in Lotus japonicus
}

Yan Du ${ }^{1,2+}$, Shanwei Luo ${ }^{1,2,3 \dagger}$, Jian Zhao ${ }^{1,4}$, Zhuo Feng ${ }^{1,2}$, Xia Chen ${ }^{1,2}$, Weibin Ren ${ }^{1,2}$, Xiao Liu ${ }^{1,2}$, Zhuanzi Wang ${ }^{1}$, Lixia Yu' ${ }^{1}$, Wenjian $\mathrm{Li}^{1}$, Ying $\mathrm{Qu}^{1,5}$, Jie Liu ${ }^{6}$ and Libin Zhou ${ }^{1,2,5^{*}}$

\begin{abstract}
Background: Flower longevity is closely related to pollen dispersal and reproductive success in all plants, as well as the commercial value of ornamental plants. Mutants that display variation in flower longevity are useful tools for understanding the mechanisms underlying this trait. Heavy-ion beam irradiation has great potential to improve flower shapes and colors; however, few studies are available on the mutation of flower senescence in leguminous plants.

Results: A mutant (C416) exhibiting blossom duration eight times longer than that of the wild type (WT) was isolated in Lotus japonicus derived from carbon ion beam irradiation. Genetic assays supported that the delayed flower senescence of $C 416$ was a dominant trait controlled by a single gene, which was located between 4,616,611 Mb and $5,331,876 \mathrm{Mb}$ on chromosome III. By using a sorting strategy of multi-sample parallel genome sequencing, candidate genes were narrowed to the gene CUFF.40834, which exhibited high identity to ethylene receptor 1 in other model plants. A physiological assay demonstrated that C416 was insensitive to ethylene precursor. Furthermore, the dynamic changes of phytohormone regulatory network in petals at different developmental stages was compared by using RNA-seq. In brief, the ethylene, jasmonic acid (JA), and salicylic acid (SA) signaling pathways were negatively regulated in C416, whereas the brassinosteroid (BR) and cytokinin signaling pathways were positively regulated, and auxin exhibited dual effects on flower senescence in Lotus japonicus. The abscisic acid (ABA) signaling pathway is positively regulated in C416.
\end{abstract}

Conclusion: So far, C416 might be the first reported mutant carrying a mutation in an endogenous ethylene-related gene in Lotus japonicus, rather than through the introduction of exogenous genes by transgenic techniques. A schematic of the flower senescence of Lotus japonicus from the perspective of the phytohormone regulatory network was provided based on transcriptome profiling of petals at different developmental stages. This study is informative for elucidating the molecular mechanism of delayed flower senescence in C416, and lays a foundation for candidate

\footnotetext{
*Correspondence: libinzhou@impcas.ac.cn

${ }^{\dagger}$ Yan Du and Shanwei Luo contributed equally to this work.

1 Biophysics Group, Biomedical Center, Institute of Modern Physics,

Chinese Academy of Sciences, 730000 Lanzhou, People's Republic

of China

Full list of author information is available at the end of the article
}

(C) The Author(s) 2021. Open Access This article is licensed under a Creative Commons Attribution 4.0 International License, which permits use, sharing, adaptation, distribution and reproduction in any medium or format, as long as you give appropriate credit to the original author(s) and the source, provide a link to the Creative Commons licence, and indicate if changes were made. The images or other third party material in this article are included in the article's Creative Commons licence, unless indicated otherwise in a credit line to the material. If material is not included in the article's Creative Commons licence and your intended use is not permitted by statutory regulation or exceeds the permitted use, you will need to obtain permission directly from the copyright holder. To view a copy of this licence, visit http://creativecommons.org/licenses/by/4.0/. The Creative Commons Public Domain Dedication waiver (http://creativeco mmons.org/publicdomain/zero/1.0/) applies to the data made available in this article, unless otherwise stated in a credit line to the data. 
flower senescence gene identification in Lotus japonicus. It also provides another perspective for the improvement of flower longevity in legume plants by heavy-ion beam.

Keywords: Lotus japonicus, Flower senescence-delayed, Carbon-ion beam irradiation, Whole genome re-sequencing, RNA-seq, Phytohormone

\section{Background}

Flower longevity is the duration of time that flowers remain open and functional. It is an important trait for ornamental plants because of its effects on floral displays. Extending flower longevity will greatly enhance the commercial value and competitiveness of ornamental plants. Furthermore, flower longevity contributes significantly to pollen dispersal and reproductive success in flowering plants. Flower senescence is a highly programmed process that is precisely controlled. Developmental (reproduction, developmental cues, growth regulators, etc.) and environmental (pollination, drought, mechanical injury, etc.) stimuli function as signals to initiate the breakdown and remobilization of cellular constituents, causing serial changes in morphological, cytological, physiological, and molecular aspects, including hormonal level imbalances; loss of membrane permeability; higher levels of oxidative and reduced levels of protective enzymes; loss of nucleic acids, proteins, and organelles; visible cell death symptoms [1]. Plant hormones, especially ethylene, are the most crucial regulators of flower senescence $[2,3]$. Patterns of flower senescence are categorized as ethylene-sensitive and ethylene-insensitive [4]. For ethylene-sensitive plant species, the increase in endogenous ethylene promotes flower senescence, and chemical or genetic modification of ethylene biosynthesis or perception genes can alter the process of flower senescence $[1,4$, 5]. In petunias, the transcription factor $\mathrm{PhFBH} 4$ interacts with the G-box cis-element in the promoter of 1-Aminocyclopropane 1-carboxylic acid (ACC) synthase 1, which is a key factor in ethylene biosynthesis. The silencing of PhFBH4 extends flower longevity, whereas overexpression lines exhibit a shorter flower lifespan [6]. Ethylenesensitive rose cultivars showed changes in the expression of RhACO1 (1-aminocyclopropane-1-carboxylate oxidase 1) [7]. Ethylene is perceived by receptors and then acts via CTR1 (constitutive triple response 1), which is a negative regulator of ethylene signaling. Downstream of the receptor-CTR1 complex is EIN2 (ethylene insensitive 2 ), which is a positive regulator of the ethylene response. Finally, the ethylene response is mediated by a series of transcriptional factors, such as EIN3 (ethylene insensitive 3) and ERF1 (ethylene response factor 1) [8, 9]. Genetic manipulation of ethylene signaling transduction factors can also modulate petal senescence [10-12]. Low levels of ethylene production are a common feature of ethylene-insensitive plants, and flower longevity usually does not respond to the application of ethylene inhibitors or exogenous ethylene. It has been reported that, cysteine protease has the potential to regulate ethylene biosynthesis and signal transduction by acting as a dual-function protein with enzymatic activity and transcriptional factor activity that bonded to the cis element to activate the expression of ACC synthesize gene. Meanwhile, the expression of cysteine proteinase is also regulated by ethylene and associated with programmed cell death or plant senescence in Arabidopsis, Dianthus caryophyllus L., Cicer arietinum L., and Brassica napus [13-17]. In addition, ethylene had been demonstrated to play special roles in regulating symbiotic nitrogen-fixation and nodulation organogenesis in legumes while influencing flower senescence [18-20]. Instead, abscisic acid (ABA) may play a primary role in these species [21]. To date, most of the knowledge of flower senescence is based on limited plant species. However, plants always make a tradeoff between investing resources in developing and maintaining flower function, and flower longevity is susceptible to climatic factors such as temperature and water availability; therefore, flower longevity is always limited in a specie specific manner for energetic and ecological reasons in nature [22, 23]. Few studies are available on flower senescence of leguminous plants, which cover 20,000 species and play important roles in agronomic activities and environmental improvement due to their nitrogenfixing ability and ornamental value. Lotus japonicus is a valuable legume that has been used as pasture for over 30 years [24]. Moreover, Lotus japonicus is also used as an ornamental plant for decorating houses and cities due to its abundant bright yellow flowers. To date, flower longevity in Lotus japonicus has not been fully characterized. Stable mutants displaying alterations in flower longevity are ideal tools for understanding the mechanism of flower longevity in Lotus japonicus.

Unrestricted to species that have a mature genetic transformation system and high-quality genome information, heavy-ion beam irradiation can induce mutations in diverse plant species by multiform sample status. Heavy-ion beam consist of ionized particles produced by heavy-ion accelerators, such as cyclotrons and synchrotrons. Because the amount of energy deposited at a unit distance of heavy-ion beam is much more intensive than that of $\gamma$-rays and $\mathrm{X}$-rays with low 
linear energy transfer (LET), heavy-ion beam irradiation can induce severe DNA damage, including DNA double-stranded breaks (DSBs) and clustered damage. Therefore, heavy-ion beam has a higher relative biological effectiveness (RBE) than $\gamma$-rays and $X$-rays [25]. If this damage is inaccurately repaired or unrepaired, mutations such as single-base substitutions (SBSs), insertions and deletions, and rearrangements are commonly induced in the genome. Some of these mutations can result in alterations in phenotype, traits and resistances. In the past decades, many mutation resources have been generated through heavy-ion beam irradiation in plants [26-37]. In our previous study, we constructed an $\mathrm{M}_{2}$ seed collection of Lotus japonicus by carbon-ion beam irradiation produced by the Heavy Ion Research Facility in Lanzhou (HIRFL). A flower senescence-delayed mutant line, C416, was isolated from the $\mathrm{M}_{2}$ population [35]. It is an ideal tool to study the mechanism of heavy-ion beam irradiation with respect to flower longevity and to provide a better understanding of the process and mechanism of senescence in Lotus japonicus.

The identification of casual genes is still a great challenge for non-model plant species and those with lowquality reference genome information. In recent years, next- generation sequencing (NGS) techniques have enabled highly reliable analytical measurements of genome variants, as well as the transcriptome in massively parallel sequencing. It has become an effective and economical tool for exploring the regulatory associations between genomic features, gene expression patterns, and phenotypic traits. For instance, by the combined use of wholegenome re-sequencing and transcriptome analysis, genes related to cadmium tolerance in C. reinhardtii and resistance to soybean (Glycine max) mosaic virus strain SC3 [38, 39], a novel single-base mutation induced by EMS in CaBRI1 that resulted in brassinosteroid accumulation, was responsible for the dwarf phenotype in peppers [40]. To explore the causal gene for the phenotype of C416, genetic mapping was carried out by association analysis of multi-sample parallel genome sequencing and rough mapping. The candidate genes were narrowed to a gene exhibited high identity to ETR1 in Glycine max, Medicago truncatula and Arabidopsis thaliana. A physiological assay was performed to test the sensitivity to ethylene precursors. Furthermore, transcriptome profiling by RNA sequencing was performed to understand flower senescence in Lotus japonicus from the perspective of the phytohormone regulatory network. These results are informative for elucidation of the molecular mechanism of delayed flower senescence in C416 and lay a foundation for candidate flower senescence gene identification in Lotus japonicus.

\section{Results}

Phenotypic characterization of the $\mathbf{C} 416$ mutant

The $C 416$ mutant was induced by carbon-ion beam irradiation in our previous study. Compared to the WT, C416 displayed distinct delayed flower senescence, with an average blossom duration of approximately 8.03 folds of the WT. Flowers of C416 did not exhibit abscission even until the plants died (Fig. 1A, B). The water loss rate of detached flowers did not differ between C416 and WT, as well as the size of pods and the number of seeds per silique (Fig. 1C-E). Interestingly, during the silique development process, curved pods were always observed in C416, although these pods would eventually straighten. These phenotypic characteristics of $C 416$ could be stably inherited by its progeny, even after continuous selfing for six generations.

\section{Genetic analysis and rough mapping of $\mathrm{C416}$}

The first steps for exploring the causal gene of $C 416$ included genetic analysis and rough mapping. It displayed a stable mutant phenotype even after continuous selfing for six generations. C416 was back-crossed with WT MG20, followed by a reciprocal cross with a polymorphic mapping parent, Gifu. Based on delayed flower senescence, $F_{1}$ and $F_{2}$ plants were genotyped unambiguously. All $F_{1}$ plants showed a mutant phenotype, indicating that the mutation of C416 was dominant. A total of $279 \mathrm{~F}_{2}$ individual plants were cultured, and the genetic segregation ratios of the mutant phenotype to those of the WT were 3:1 (Table 1). These results indicated that the mutant trait of $C 416$ was under the control of a single dominant gene. $\mathrm{F}_{2}$ plants with the WT phenotype were selected for rough mapping because they were homozygous for the recessive allele. First, by using SSR markers and 23 individual plants, the mutation locus was roughly positioned on chromosome III and closely linked to the marker TM0080 based on the lowest exchange rate (4\%) (Fig. 2A and Fig. S1). To further narrow down the region that contains the responsible gene, amplified mapping population and dense markers were used to find the closer recombination end-points on either side of the target gene (C416) (Fig. 2B). Finally, the candidate region was narrowed down to between TM0282 and TM0436, with an interval of 1.2 centimorgan (cM) (Fig. 2C).

\section{Association analysis of genetic mapping and re-sequencing of $C 416$}

We re-sequenced C416, as well as five other lines derived from carbon-ion beam irradiation. Mutations that were unique to $C 416$ were detected by ruling out the background mutations shared by any two samples, as reported in our previous studies [41]. Several variants were randomly selected for verification by Sanger sequencing 

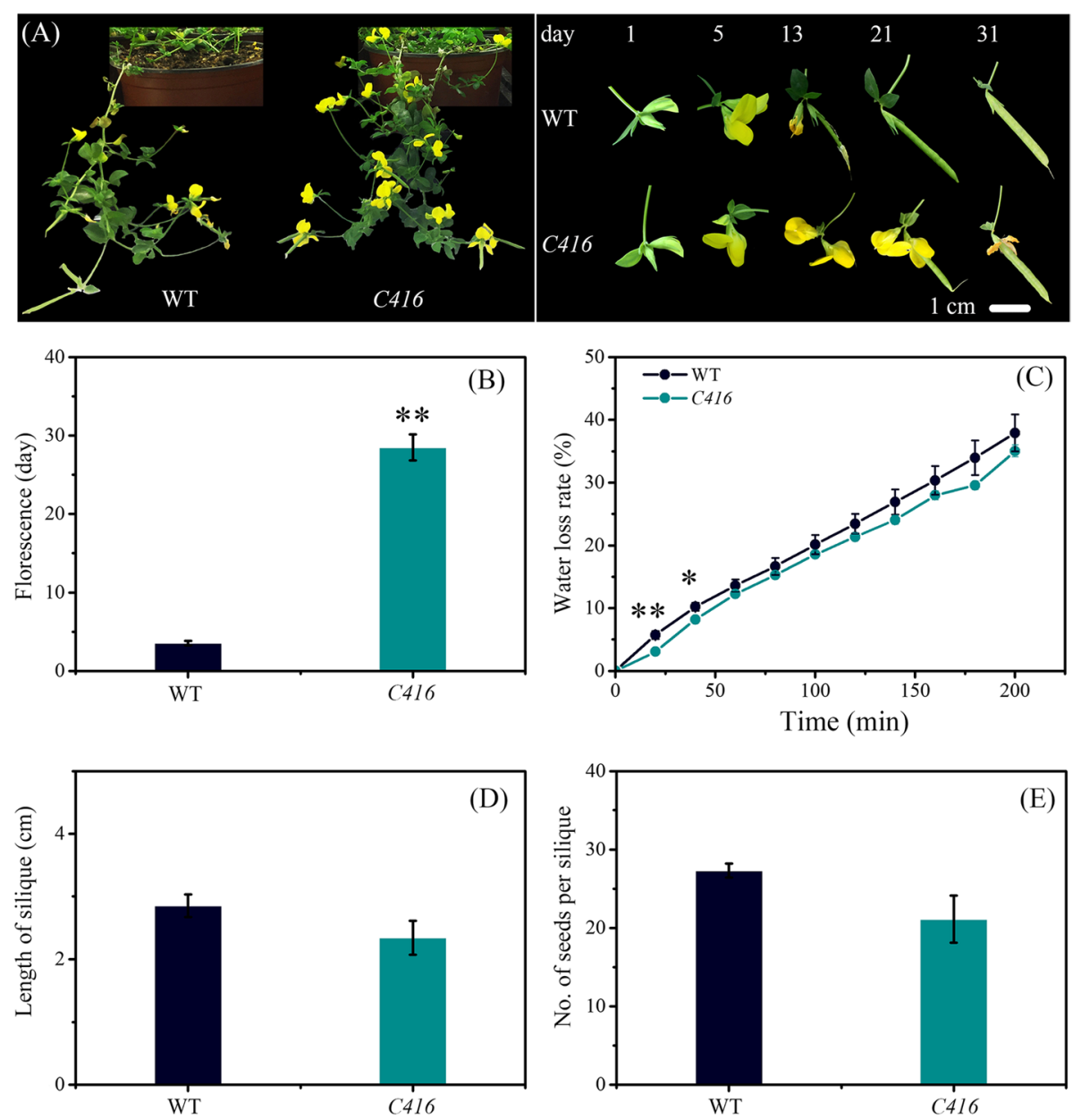

Fig. 1 Phenotypic and physiological characteristics of reproductive stages. A Phenotypes of WT and C416. B Floral longevity of WT and C416. C Water loss rate of detached flowers of WT and C416. D Pod length, E Average number of seeds per pod. The data points are mean \pm standard error of three replications

Table 1 The number of different phenotypic seedlings segregated in the offspring of a reciprocal cross

\begin{tabular}{|c|c|c|c|c|c|}
\hline \multirow[t]{2}{*}{ Cross } & \multirow[t]{2}{*}{$F_{1}$ phenotype } & \multicolumn{2}{|c|}{ Number of seedlings in $F_{2}$} & \multirow[t]{2}{*}{ Expect ratio of $C 416 / \mathrm{WT}$} & \multirow[t]{2}{*}{ Chi-square ( $P$-value) } \\
\hline & & WT & C416 & & \\
\hline 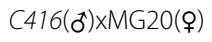 & $C 416$ & 15 & 34 & $3: 1$ & $0.823(P=0.364)$ \\
\hline$M G 20\left(0^{*}\right) \times C 416(9)$ & $C 416$ & 10 & 31 & $3: 1$ & $0.008(P=0.928)$ \\
\hline Gifu(o)xC416(ð) & $C 416$ & 51 & 138 & $3: 1$ & $0.397(P=0.529)$ \\
\hline
\end{tabular}

(See figure on next page.)

Fig. 2 Genetic mapping of C416. A Colormap of the initial mapping of the C416 mutation. B Colormap of genotyping based on amplified bands by markers in chromosome III. From top down are the chromosome number, TM marker number, and number of individual plant tested with microsatellite markers from different chromosomal regions. P: homozygous Lotus japonicus MG-20, G: homozygous Lotus japonicus Gifu B-129, H: heterozygous, ND: not detected. Recombination rate $=\frac{(\mathrm{H}+2 \mathrm{P})}{2 \mathrm{~N}}$, 'N'indicates the total number of plants. C Overview of genetic mapping of $\mathrm{C} 416$ 
(A)

\begin{tabular}{|c|c|c|c|c|c|c|c|c|c|c|c|c|}
\hline $\mathrm{Chr}$ & \multicolumn{3}{|c|}{ I } & \multicolumn{3}{|c|}{ II } & \multicolumn{3}{|c|}{ III } & IV & $\mathrm{V}$ & $\mathrm{VI}$ \\
\hline Marker & 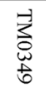 & $\begin{array}{l}\frac{1}{3} \\
0 \\
0 \\
0\end{array}$ & 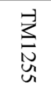 & $\begin{array}{l}\overrightarrow{3} \\
\text { 空 } \\
\text { in }\end{array}$ & $\begin{array}{l}\overrightarrow{3} \\
\frac{3}{\infty}\end{array}$ & $\begin{array}{l}\vec{z} \\
\text { 忍 } \\
\text { 柋 }\end{array}$ & $\begin{array}{l}\overrightarrow{3} \\
3 \\
8 \\
0\end{array}$ & $\begin{array}{l}\overrightarrow{3} \\
3 \\
8 \\
8 \\
0\end{array}$ & 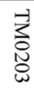 & $\begin{array}{l}\vec{z} \\
\text { 总 } \\
\text { 心ू }\end{array}$ & \begin{tabular}{l}
$\overrightarrow{3}$ \\
3 \\
\multirow{3}{*}{}
\end{tabular} & $\begin{array}{l}-1 \\
3 \\
\text { s. } \\
\text { s. }\end{array}$ \\
\hline Plant-1 & $\mathrm{P}$ & $\mathrm{P}$ & $\mathrm{P}$ & ND & $\mathrm{P}$ & $\mathrm{P}$ & G & G & $\mathrm{H}$ & $\mathrm{H}$ & G & $\mathrm{H}$ \\
\hline Plant-2 & G & $\mathrm{P}$ & ND & $\mathrm{H}$ & $\mathrm{P}$ & ND & G & $\mathrm{H}$ & $\mathrm{P}$ & $\mathrm{H}$ & $\mathrm{H}$ & $\mathrm{H}$ \\
\hline Plant-3 & $\mathrm{P}$ & $P$ & $\mathrm{P}$ & $\mathrm{H}$ & $\mathrm{P}$ & $\mathrm{P}$ & G & $\mathrm{H}$ & $\mathrm{H}$ & $\mathrm{H}$ & G & $\mathrm{P}$ \\
\hline Plant-4 & $\mathrm{P}$ & $\mathrm{P}$ & $\mathrm{P}$ & $\mathrm{H}$ & $\mathrm{P}$ & $\mathrm{P}$ & G & G & G & $\mathrm{H}$ & $\mathrm{G}$ & $\mathrm{P}$ \\
\hline Plant-5 & $\mathrm{P}$ & $P$ & $P$ & G & $\mathrm{P}$ & $\mathrm{P}$ & G & G & $\mathrm{P}$ & $\mathrm{H}$ & $\mathrm{H}$ & $\mathrm{H}$ \\
\hline Plant-6 & $\mathrm{H}$ & $\mathrm{H}$ & P & $\mathrm{H}$ & P & ND & G & P & $\mathrm{H}$ & G & $\mathrm{G}$ & G \\
\hline Plant-7 & $\mathrm{P}$ & $\mathrm{P}$ & $\mathrm{H}$ & $\mathrm{P}$ & $\mathrm{H}$ & $\mathrm{H}$ & G & G & G & G & $\mathrm{H}$ & G \\
\hline Plant-8 & $\mathrm{P}$ & $P$ & $P$ & $\mathrm{H}$ & $\mathrm{P}$ & $P$ & G & $P$ & $\mathrm{H}$ & $\mathrm{H}$ & $\mathrm{H}$ & $\mathrm{H}$ \\
\hline Plant-9 & $\mathrm{H}$ & $P$ & $P$ & $\mathrm{H}$ & $\mathrm{H}$ & $\mathrm{H}$ & G & $\mathrm{P}$ & $\mathrm{P}$ & $\mathrm{H}$ & $\mathrm{H}$ & $\mathrm{P}$ \\
\hline Plant -10 & $\mathrm{H}$ & G & $P$ & G & $\mathrm{H}$ & P & G & G & $\mathrm{H}$ & $\mathrm{P}$ & $\mathrm{P}$ & $\mathrm{H}$ \\
\hline Plant-11 & $\mathrm{H}$ & G & $\mathrm{H}$ & $\mathrm{P}$ & $\mathrm{H}$ & G & G & $\mathrm{H}$ & $\mathrm{H}$ & $P$ & G & $\mathrm{H}$ \\
\hline Plant-12 & $\mathrm{H}$ & $\mathrm{H}$ & $\mathrm{H}$ & $\mathrm{G}$ & $\mathrm{H}$ & G & $\mathrm{H}$ & $\mathrm{G}$ & $\mathrm{G}$ & $\mathrm{H}$ & $\mathrm{P}$ & $P$ \\
\hline Plant-13 & $\mathrm{P}$ & $\mathrm{P}$ & $\mathrm{H}$ & $\mathrm{P}$ & $\mathrm{P}$ & $\mathrm{P}$ & G & G & G & G & G & $\mathrm{H}$ \\
\hline Plant-14 & $\mathrm{H}$ & $\mathrm{H}$ & $\mathrm{P}$ & $P$ & G & $\mathrm{H}$ & G & G & G & $\mathrm{H}$ & $\mathrm{P}$ & $\mathrm{P}$ \\
\hline Plant-15 & $\mathrm{H}$ & $\mathrm{P}$ & $\mathrm{H}$ & $\mathrm{H}$ & G & G & G & $\mathrm{H}$ & $\mathrm{H}$ & $\mathrm{H}$ & $\mathrm{H}$ & $P$ \\
\hline Plant-16 & $\mathrm{H}$ & P & $\mathrm{H}$ & $\mathrm{H}$ & G & $\mathrm{P}$ & $\mathrm{H}$ & $\mathrm{P}$ & $\mathrm{P}$ & $\mathrm{H}$ & $\mathrm{P}$ & P \\
\hline Plant-17 & P & G & $\mathrm{H}$ & $P$ & $\mathrm{H}$ & P & G & P & G & G & $\mathrm{P}$ & $\mathrm{H}$ \\
\hline Plant-18 & $\mathrm{H}$ & $\mathrm{P}$ & G & $\mathrm{H}$ & $\mathrm{H}$ & $\mathrm{H}$ & G & G & $\mathrm{H}$ & $\mathrm{H}$ & $\mathrm{H}$ & $\mathrm{H}$ \\
\hline Plant-19 & $\mathrm{H}$ & $P$ & $P$ & ND & $\mathrm{H}$ & P & G & $\mathrm{H}$ & $\mathrm{H}$ & G & $\mathrm{H}$ & $\mathrm{P}$ \\
\hline Plant-20 & $\mathrm{P}$ & $P$ & $\mathrm{P}$ & G & $\mathrm{P}$ & $\mathrm{P}$ & G & G & G & $\mathrm{H}$ & $\mathrm{H}$ & $\mathrm{H}$ \\
\hline Plant-21 & $\mathrm{P}$ & $\mathrm{P}$ & $P$ & $\mathrm{H}$ & $\mathrm{H}$ & G & G & $\mathrm{H}$ & G & $\mathrm{P}$ & G & $\mathrm{P}$ \\
\hline Plant-22 & $\mathrm{P}$ & $\mathrm{P}$ & $\mathrm{P}$ & G & $\mathrm{P}$ & $\mathrm{P}$ & G & $\mathrm{H}$ & $\mathrm{H}$ & $\mathrm{H}$ & G & $\mathrm{H}$ \\
\hline Plant-23 & $\mathrm{P}$ & $\mathrm{P}$ & $\mathrm{P}$ & ND & $\mathrm{P}$ & $\mathrm{P}$ & G & G & $\mathrm{P}$ & $\mathrm{P}$ & $\mathrm{H}$ & $\mathrm{P}$ \\
\hline $\begin{array}{l}\text { Recombination } \\
\text { rates }(\%)\end{array}$ & 74 & 78 & 80 & 50 & 70 & 71 & 4 & 37 & 43 & 46 & 43 & 59 \\
\hline
\end{tabular}

(B)

\begin{tabular}{|c|c|c|c|c|c|}
\hline Marker & TM0666 & TM0282 & TM0436 & TM0080 & Direction \\
\hline Position (Mb) & 3.1 & 4.1 & 5.3 & 6.1 & \\
\hline Plant-13 & H & H & G & G & Left of TM0436 \\
\hline Plant-14 & H & H & G & G & Left of TM0436 \\
\hline Plant-34 & G & G & H & H & Right of TM0282 \\
\hline Plant-48 & H & H & G & G & Left of TM0436 \\
\hline Plant-63 & G & G & H & H & Right of TM0282 \\
\hline Plant-67 & H & H & G & ND & Left of TM0436 \\
\hline Plant-76 & H & H & G & G & Left of TM0436 \\
\hline Plant-104 & H & H & G & G & Left of TM0436 \\
\hline
\end{tabular}

(C)

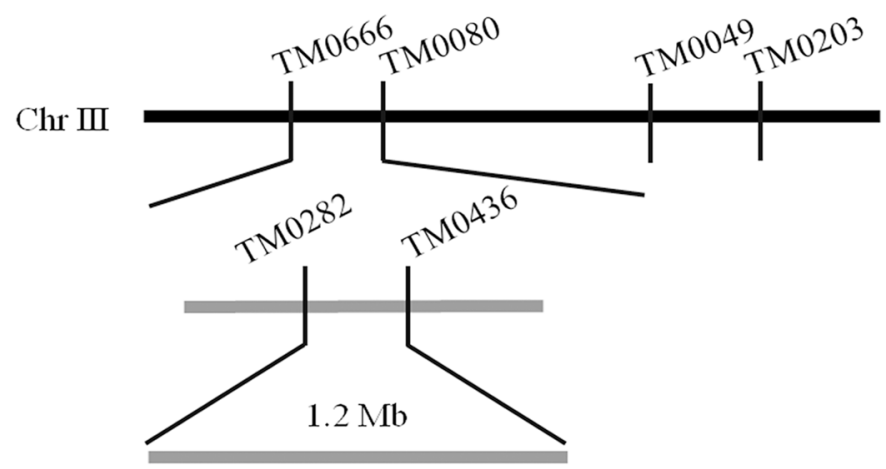

Fig. 2 (See legend on previous page.) 
(Fig. S2) to verify the reliability of the re-sequencing. As C416 is a stable mutant line, only homozygous variants in the genome were considered in the present study. A total of 261 homozygous mutations composed of 191 SBSs (73.18\%), 55 deletions (21.07\%), and 15 insertions (5.75\%) were detected in six plants. Among the 261 homozygous mutations, 62 variants consisting of 49 SBSs, 10 deletions, and 3 insertions, were unique to the $C 416$ genome. In detail, there were $21,16,6,6,8,2$, and 3 mutations located in chromosome 0 , I, II, III, IV, V and VI, respectively (Table S1). Fifty-six candidate genes remained after ruling out those located in the intergenic and intron regions. Associated with the rough mapping of C416, we focused on the mutated genes on chromosome III and as well as chromosome 0 , as the Lotus japonicus genome assembly version 3.0 has $162 \mathrm{Mb}$ of the genome assigned to a virtual chromosome 0 . Finally, only 22 genes were sorted out. Among these, only 12 genes had functional annotations or predictions (Table 2). In the rough mapping region, CUFF.40834 showed a thymine $\rightarrow$ cytosine single base substitution in exon resulting in a change in amino acid from leucine to serine. The structure and physicochemical property prediction of CUFF.40834 protein was shown in Fig. 3A. Bioinformatics analysis showed that the theoretical molecular weight of CUFF.40834 protein was 824,441.01, theoretical isoelectric point was 7.06 , the highest abundant amino acid was Leu, accounting for $12.4 \%$, the grand average of hydropathicity was 0.135 . In addition, CUFF.40834 was predicted to subcellular localized on endoplasmic reticulum. The protein blast results showed that CUFF.40834 exhibited high homology to ETR1, which was well characterized in Arabidopsis thaliana, Glycine max and Medicago truncatula (Fig. 3B). This mutation was indirectly verified by RT-qPCR by designing primers around the mutation site (Fig. S3). By combining of the above results, we preliminarily inferred that CUFF.40834 might be the causal gene for the extended flower longevity of C416.

\section{Sensitivity of $C 416$ and WT to the ethylene precursor}

Based on the indication provided by the genetic mapping, we examined the sensitivity of both C416 and WT to the ethylene precursor ACC. Triple response (hooks, lateral expansion, and dwarfing) assay was carried out in the early developmental stage. The C416 and WT were germinated on $1 / 2 \mathrm{MS}$ containing $0-50 \mu \mathrm{M} \mathrm{ACC}$ in the dark for 10 days. The dark-grown seedlings of C416 did not respond to the application of ACC, as no difference was observed between the treatment and control groups. The WT showed hooked, thickened, and dwarf hypocotyls after treatment with ACC (Fig. 4A, C). In addition, in light conditions, $C 416$ also showed a significant difference in response to ACC in root development, including the length and root hair, when compared with the WT (Fig. 4B, D). The expression level of EIN2, an important gene involved in ethylene biosynthesis and signal transduction, was also examined (Fig. 4E). The extent of the WT response to ACC appeared stronger than that of the C416 based on the expression patterns of LjEIN2 (CUFF.32775); the expression was significantly lower in the $C 416$ after $2 \mathrm{~h}$ of treatment with $5 \mu \mathrm{M}$ ACC than that in the WT. During the reproduction stage, the detached flowers were treated with $100 \mu \mathrm{M} \mathrm{ACC}$ and $\mathrm{dd}_{2} \mathrm{O}$ for 1 week. ACC treatment did not promote senescence of the detached flowers in C416, as no brown area was observed in the petals, whereas obvious brown area appeared in the WT petals in the ACC treatment group (Fig. 4F). These results indicate that $C 416$ is insensitive

Table 2 Homozygous mutations located in chromosome 0 and chromosome III detected in C416 genome by re-sequencing ${ }^{a}$

\begin{tabular}{|c|c|c|c|c|c|c|}
\hline Chr & Position & Reference & Alteration & Type & ID & Function annotation \\
\hline 0 & $5,211,768$ & $\mathrm{~T}$ & A & SBS & CUFF.738 & Zinc finger $\mathrm{CCCH}$ domain-containing protein \\
\hline 0 & $18,170,144$ & A & $\mathrm{T}$ & SBS & CUFF.2453 & Cytochrome P450 94A1-like \\
\hline 0 & $48,986,237$ & G & A & SBS & CUFF.6544 & Chloroplast-targeted copper chaperone protein \\
\hline 0 & $116,649,426$ & $\mathrm{~T}$ & C & SBS & CUFF.14705 & TashAT2 \\
\hline 0 & $125,393,533$ & G & A & SBS & CUFF.15787 & F-box \\
\hline 0 & $146,760,633$ & G & A & SBS & CUFF.18858 & F-box/FBD/LRR-repeat protein At5g56420-like \\
\hline 0 & $149,463,384$ & G & $-15^{b}$ & Deletion & CUFF.19232 & Cysteine proteinase precursor \\
\hline 0 & $157,428,073$ & A & $\mathrm{T}$ & SBS & CUFF.20352 & Probable protein phosphatase $2 \mathrm{C} 60$-like isoform $\mathrm{X} 1$ \\
\hline 0 & $174,990,604$ & $\mathrm{~T}$ & C & SBS & CUFF.22836 & EMB1273 \\
\hline 3 & $4,271,744$ & $\mathrm{~T}$ & G & SBS & CUFF.40793 & TMV resistance protein $\mathrm{N}$-like \\
\hline 3 & $38,052,958$ & $\mathrm{~T}$ & $+\mathrm{TTC}$ & Insertion & CUFF.45186 & DNA ligase \\
\hline 3 & $4,982,946$ & $\mathrm{~T}$ & C & SBS & CUFF.40834 & Signal transduction response regulator \\
\hline
\end{tabular}

anly mutations that located in genes with definite function prediction were shown here

${ }^{b}$ Insertions or deletions in size above 5 bp were displayed by ${ }^{\prime}+{ }^{\prime}$ or '-'followed by the length of mutation fragments 

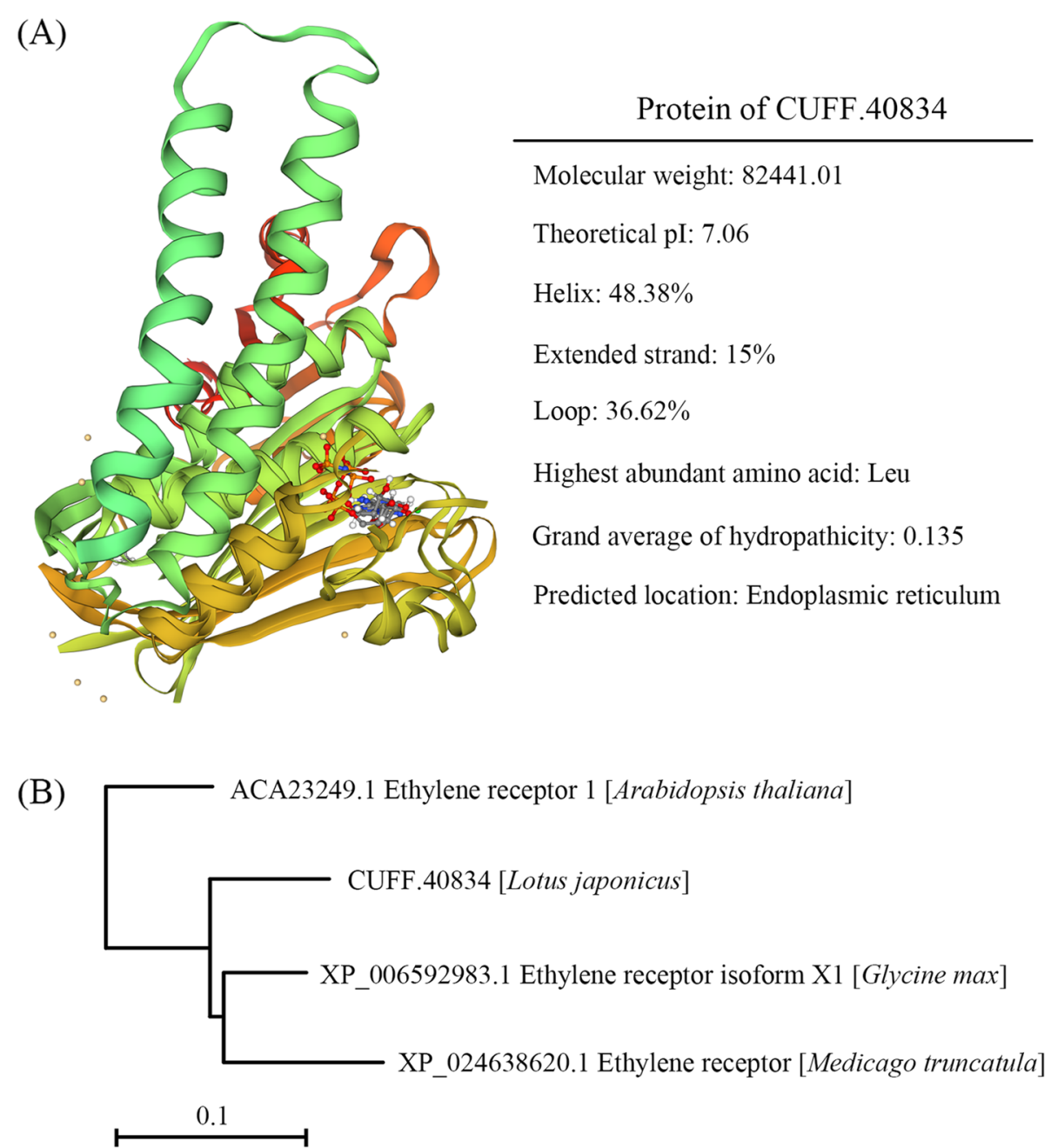

Fig. 3 Bioinformatic analysis of CUFF.40834 protein. A Structure prediction, subcellular localization prediction and physicochemical property analysis of CUFF.40834. B Phylogenetic analysis based on amino acid alignment, unrooted phylogenetic tree of CUFF.40834 and its homologous proteins in Arabidopsis thaliana, Glycine max and Medicago truncatula

to ethylene, which may be caused by abnormal ethylene signal transduction.

\section{Comparison of petal transcriptional profile between WT and $\mathrm{C} 416$}

To explore the molecular aspects of the $C 416$ petal senescence process based on the phytohormone regulation, transcriptome profiles were generated by RNA-seq analysis. Petals were harvested 2 days before pollination (S1),
2 days after pollination (S2) and 8 days after pollination (S3, only for C416) were used for RNA-Seq (Fig. 5A). A total of 917,203,062 raw reads were generated for 15 petal samples and 22 to 44 million clean reads for each sample (Supplementary Table A.1). The numbers of differentially expressed genes (DEGs) were shown in Fig. 5B. The biggest difference was detected in S1 vs. S2 and S1 vs. S3. For instance, in $\mathrm{C} 416-\mathrm{S} 1$ vs. C416-S2, there were 9502 DEGs were detected, whereas, only 341 DEGs were

(See figure on next page.)

Fig. 4 Sensitivity of WT and C416 to ACC. Phenotype of hypocotyls (A) and root (B). C Hypocotyls length of seedlings germinated on ACC with different concentration for 10 days (in the dark). D Root length of seedlings germinated on ACC with different concentration for 10 days (under light condition) (E) Relative expression level of LjEIN2. Seedlings were transferred to the 1/2 MS medium with 0 and $5 \mu M$ ACC and the expression level of LjEIN2 was examined at the indicated time. Control represents untreated seedlings. Data are means \pm standard error of three biological replications. F, Response of detached flower in different stages to ACC treatment. Scale bar, $1 \mathrm{~cm}$ 


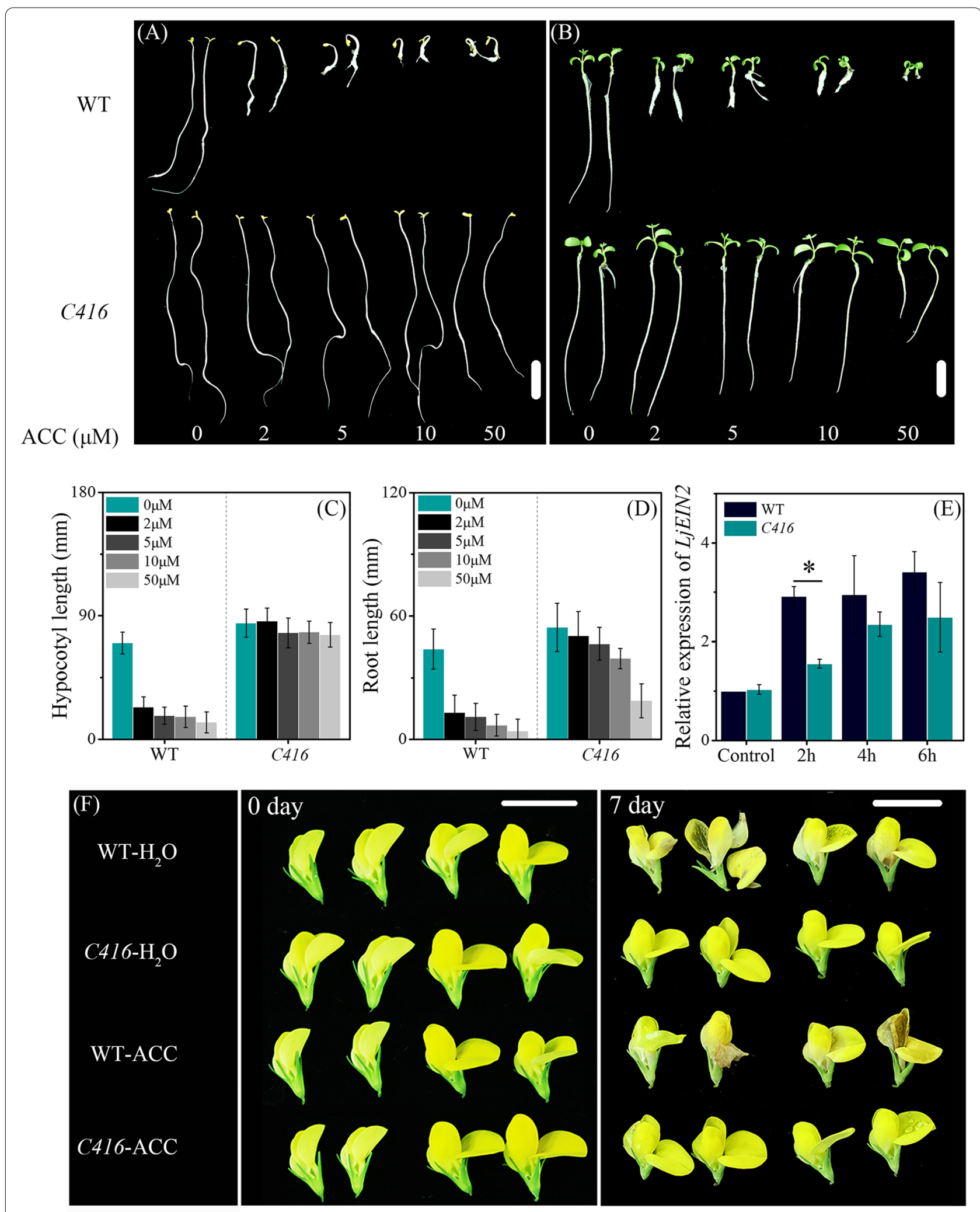

Fig. 4 (See legend on previous page.) 
detected in C416-S2 vs. C416-S3 (Fig. 5B). In addition, for WT vs. C416, there were more DEGs were detected in S2 than that in S1. In detail, four and five genes exhibited up- and down-regulated expression patterns at S1, respectively, whereas, 412 and 394 DEGs were up- and down-regulated at S2 (Fig. 5B). Eighteen genes were selected to test the correlation coefficient between RNAseq and RT-qPCR, the $\mathrm{R}^{2}$ was calculated as 0.85 , and expression patterns showed high consistency, all of which indicated that the results of RNA-seq are reliable for further study (Fig. 5C, Fig. S4 and Fig. S5). In addition, five DEGs were shared between these two stages (Fig. 5D). In S1 vs. S2, more than 9000 DEGs were detected in both the WT and C416, and 6805 DEGs were shared by these two lines (Fig. 5D).

Flower senescence in Lotus japonicus from the perspective of plant hormone regulatory network

DEGs in WT-S1 vs. C416-S1 and WT-S2 vs. C416-S2, as well as those DEGs with different expression models among WT-S1 vs. WT-S2, C416-S1 vs. C416-S2 were mainly considered in the present study. Among these, DEGs involved in phytohormone signal transduction processes were screened out in the subsequent analysis, as they play important roles in plant senescence (Fig. 5E). In the case of WT-S1 vs. C416-S1 and WT-S2 vs. C416-S2, five DEGs were identified in the ethylenemediated signaling pathway; five in the auxin-mediated signaling pathway; and one in salicylic acid (SA), jasmonic acid (JA), cytokinin, and ABA -mediated signaling pathways (Fig. 6A). Figure 6A shows the expression patterns of all these genes, as well as genes involved in nodulation, cysteine proteinase as they showed definite regulatory effects on ethylene (biosynthesis or signaling transduction) and flower senescence in previous studies. Ethylene receptor ETR2, ethylene-responsive transcription factors WIN1, TINY, RAP2-3, and ERF010 were downregulated in C416-S2 when compared with those of WT-S2. CUFF.19232, which encodes a cysteine protease, was down regulated in C416-S2. CUFF.8415 and CUFF.8416 which involved in nodulation were up regulated in C416-S2. TGA3 (SA response factor) and JAR1 (jasmonic acid amino synthetase) were also downregulated in C416-S2. Auxin response factor $A R F 1$, auxin-induced protein $15 A$ and $X 10 A, A R G 7$ and GH3.1, two-component response regulator ARR11 (cytokinin signaling pathway), and SNF1-related protein kinase
SRK21 (ABA signaling pathway) were upregulated in C416-S2. In the case of WT-S1 vs. WT-S2 and C416-S1 vs. C416-S2 (Fig. 6B), four DEGs were involved in the ethylene signaling pathway (EBF1, EIN3, ETR2, and ERS1), seven in the auxin signaling pathway (SAUR-like gene, auxin transporter-like protein 2, AUX28, IAA13, $I A A 26$, and GH3.6), three in cytokinin signaling pathway (AHP4, ARR9, and ARR12), one in the SA signaling pathway (TGA3), two in the ABA signaling pathway (Protein phosphatase 2C, PP2C), two in the JA signaling pathway (MYC2), one in the brassinosteroids (BR) signaling pathway (BAK1) and one in the gibberellic acid (GA) signaling pathway (GID2) exhibited different expression change tendencies between the WT and C416 (Fig. 6B). Overall, the $C 416$ mutation led to differential expression of a series of genes that are involved in multiple phytohormone signaling pathways (Fig. 7). In brief, ethylene, JA, and SA signaling pathways were negatively regulated in C416, whereas the BR and cytokinin signaling pathway were positively regulated, and auxin exhibited dual effects on flower senescence in Lotus japonicus. The ABA signaling pathway was positively regulated in C416, and ABA might be the major phytohormone factor that promotes senescence when the ethylene signaling pathway is blocked in Lotus japonicus.

\section{Discussion}

Petal senescence is the last stage of flower development and is a precisely regulated and irreversible programmed process. The life span of flowers is limited by species-specific, ecological and energetic factors [42]. Mutants displaying longer or shorter flower life expectancy are useful tools for understanding the mechanism of the senescence process. It also greatly improves the commercial value of ornamental plants. Compared with those for flower shape and color, mutations in flower senescence have seldom been reported in the history of mutation breeding by heavy-ion beam irradiation. By using carbon-ion beam irradiation, a mutant (C416) that exhibited delayed flower senescence and abscission was isolated in Lotus japonicus; its florescence extended to almost eight times longer than that of the WT.

Precise exploration of the causal gene through omics studies might be relatively more difficult for Lotus japonicus as $41.12 \%$ of the genome was unanchored to a specific chromosome. The Lotus japonicus genome assembly version 3.0 was constructed by a hybrid assembly integrating

(See figure on next page.)

Fig. 5 A global view of transcriptome dynamics in petals of WT and C416. A Stage of flower development in Lotus japonicus and samples used for RNA-Seq. B Statistical analysis of DEGs at different stages. CThe correlation coefficient between RNA-seq and RT-qPCR data base on 18 genes. D Venn diagrams showing the distribution of DEGs in WT-S1 vs. C416-S1 and WT-S2 vs. C416-S2 (left), and in WT-S1 vs. WT-S2, C416-S1 vs. C416-S2 and C416-S1 vs. C416-S3 (right). E List of DEGs involved in phytohormone signal transduction 
(A)

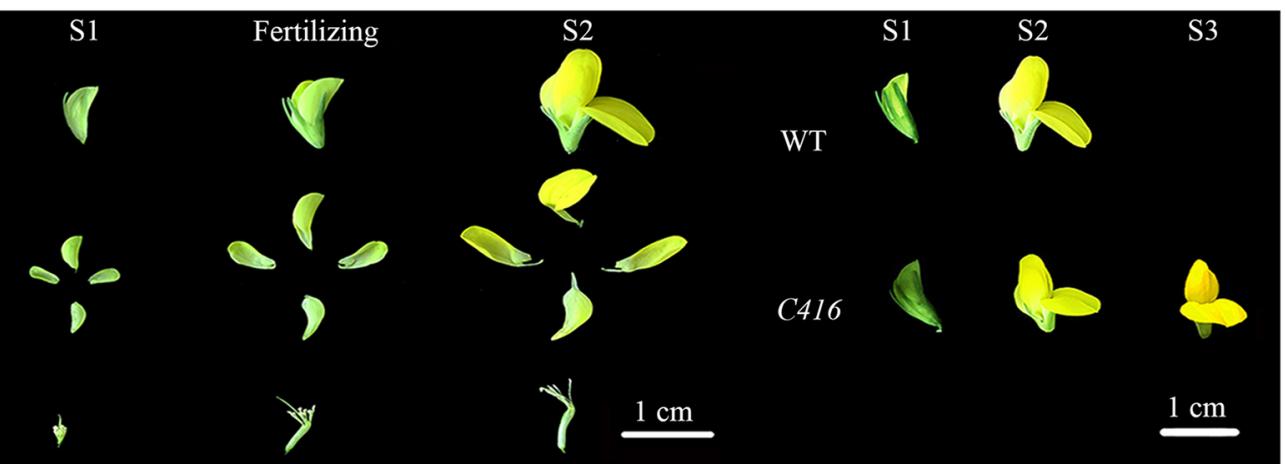

(B)
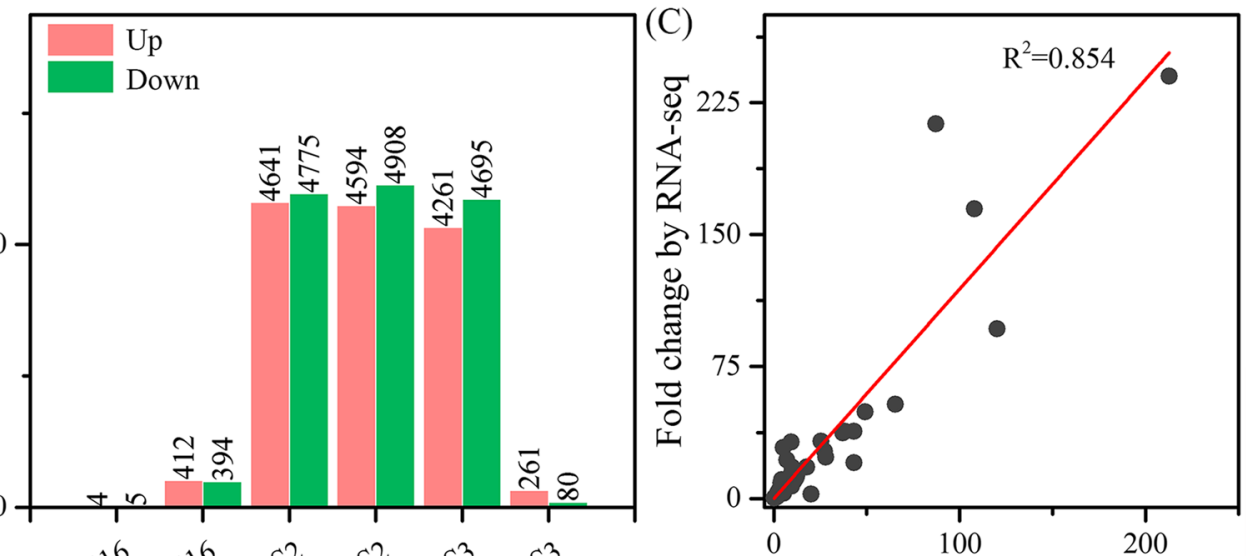

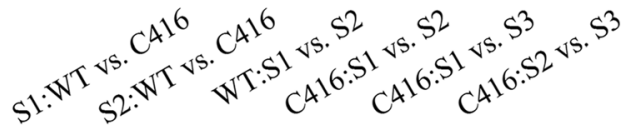

Fold change by qRT-PCR

(D)
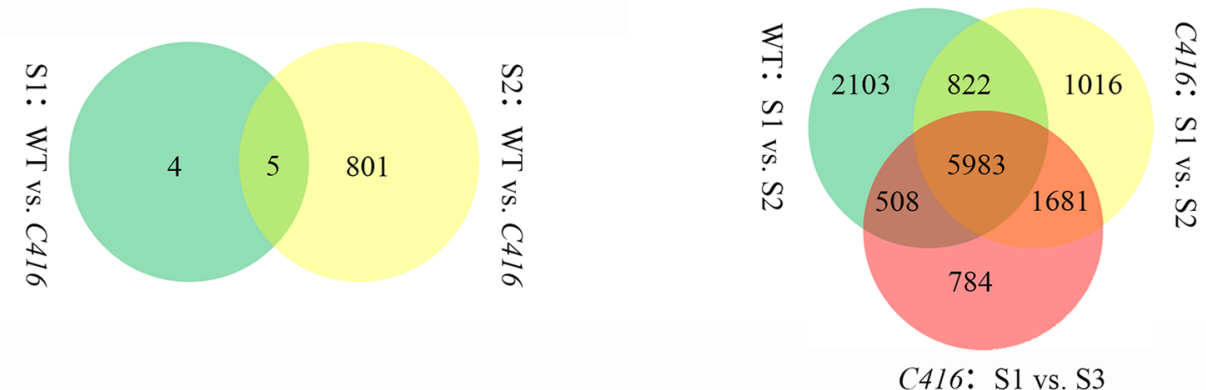

(E)

\begin{tabular}{|c|c|c|c|c|c|c|c|}
\hline Ethylene & Auxin & Cytokinin & SA & ABA & JA & $\mathrm{BR}$ & GA \\
\hline CUFF.10194 & CUFF.36489 & CUFF. 12360 & CUFF.26225 & CUFF.38093 & CUFF.44630 & NODE_12853 & CUFF.52767 \\
\hline CUFF. 15880 & CUFF.45794 & CUFF.40421 & & CUFF.50403 & CUFF. 15527 & & \\
\hline CUFF.20977 & CUFF.45797 & CUFF.28101 & & CUFF.19081 & CUFF.23560 & & \\
\hline CUFF.50709 & CUFF.5099 & CUFF.26404 & & & & & \\
\hline CUFF. 8738 & CUFF.6621 & & & & & & \\
\hline CUFF.3781 & CUFF. 8322 & & & & & & \\
\hline CUFF.43031 & CUFF.16426 & & & & & & \\
\hline CUFF. 33502 & CUFF.20463 & & & & & & \\
\hline & NODE_35381 & & & & & & \\
\hline & CUFF. 23587 & & & & & & \\
\hline & CUFF. 40435 & & & & & & \\
\hline
\end{tabular}

Fig. 5 (See legend on previous page.) 


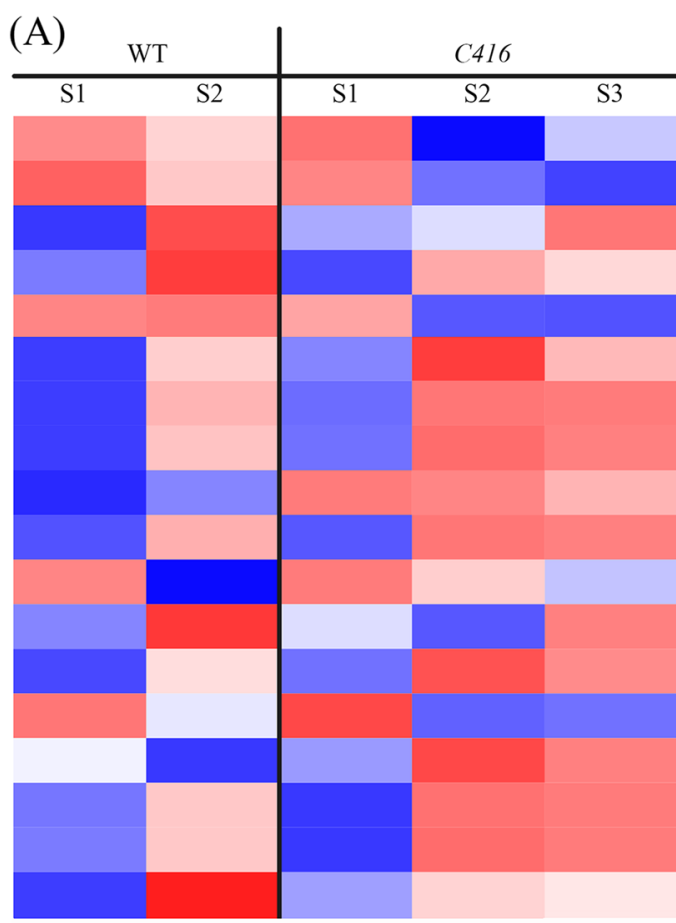

\begin{tabular}{ll}
\multicolumn{1}{c}{ ID } & Description \\
CUFF.10194 & Ethylene receptor 2 \\
CUFF.15880 & Ethylene-responsive transcription factor WIN1 \\
CUFF.20977 & Ethylene-responsive transcription factor ERF010 \\
CUFF.50709 & Ethylene-responsive transcription factor RAP2-3 \\
CUFF.8738 & Ethylene-responsive transcription factor TINY \\
CUFF.36489 & Probable indole-3-acetic acid-amido synthetase GH3.1 \\
CUFF.45794 & Indole-3-acetic acid-induced protein ARG7 \\
CUFF.45797 & Auxin-induced protein X10A \\
CUFF.5099 & Auxin response factor 1 \\
CUFF.6621 & Auxin-induced protein 15A \\
CUFF.12360 & Two-component response regulator ARR11 \\
CUFF.26225 & Transcription factor TGA3 \\
CUFF.38093 & Serine/threonine-protein kinase SRK21 \\
CUFF.44630 & Jasmonic acid-amido synthetase JAR1 \\
CUFF.55905 & Nodulation receptor kinase \\
CUFF.8415 & Flotillin-like protein 4 \\
CUFF.8416 & Flotillin-like protein 1 \\
CUFF.19232 & KDEL-tailed cysteine endopeptidase CEP1
\end{tabular}

(B)

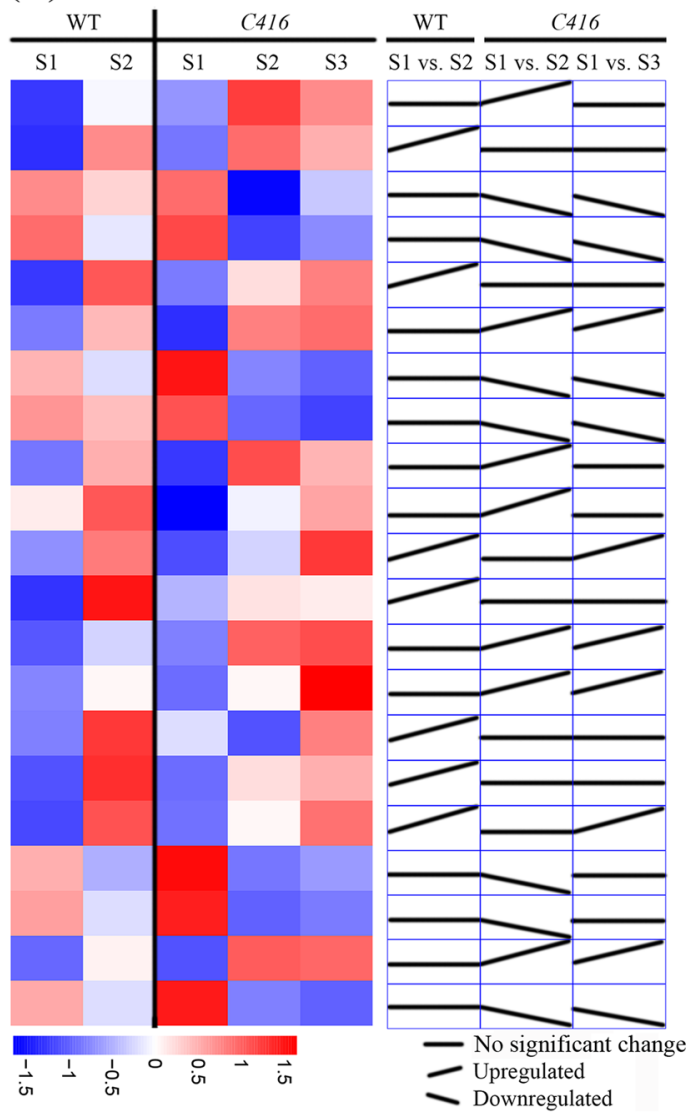
ID Description

\section{CUFF.3781 EIN3-binding F-box protein 1}
CUFF.43031 Ethylene insensitive 3-like protein
CUFF.10194 Ethylene receptor 2
CUFF.33502 Ethylene response sensor 1
CUFF.8322 SAUR-like auxin-responsive protein
CUFF.16426 Auxin response factor 9
CUFF.20463 Auxin transporter-like protein 2
NODE 35381 Auxin-induced protein AUX28
CUFF.23587 Auxin-responsive protein IAA13
CUFF.40435 Auxin-responsive protein IAA26
CUFF.16719 Indole-3-acetic acid-amido synthetase GH3.6
CUFF.40421 Histidine-containing phosphotransfer protein 4
CUFF.28101 Two-component response regulator ARR12
CUFF.26404 Two-component response regulator ARR9
CUFF.26225 Transcription factor TGA3
CUFF.50403 Probable protein phosphatase 2C
CUFF.19081 Protein phosphatase 2C
CUFF.15527 Transcription factor MYC2
CUFF.23560 Transcription factor MYC2
NODE_12853 BRI1-associated receptor kinase 1
CUFF.52767 F-box protein GID2

Fig. 6 Expression pattern of phytohormone-related genes during petal senescence. A, Expression level of DEGs in both of WT-S1 VS. C416-S1 and WT-S2 vs. C416-S2. B, Expression analysis of genes with different expression trend between WT-S1 vs. WT-S2 and C416-S1 vs. C416-S2 


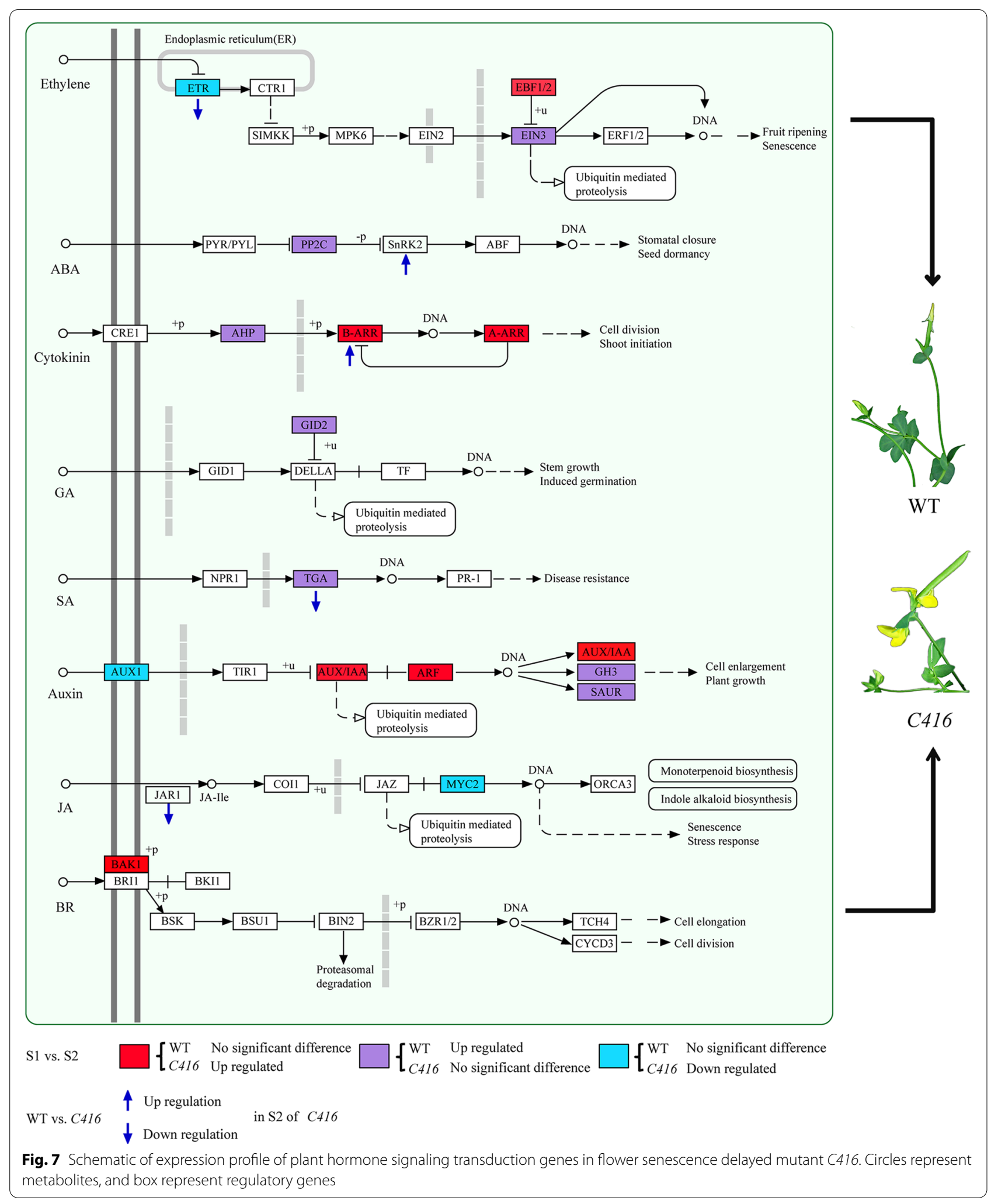


Sanger-sequencing data from TAC/BAC clones and shotgun approaches with Illumina sequencing data to $40 \times$ genome coverage. A total of 132 scaffolds covering $232 \mathrm{Mb}$ were aligned to six Lotus japonicus chromosomes. The 23,572 contigs, corresponding to $162 \mathrm{Mb}$ of the genome, were assigned to the virtual chromosome 0 [43]. In this study, we integrated and associated the results in the following aspects: Genetic assay supported that the mutation phenotype of C416 was a dominant trait controlled by a single gene, which was located between 4,616,611 $\mathrm{Mb}$ and 5,331,876 $\mathrm{Mb}$ in chromosome III (Fig. 2 and Table 1). Using a sorting strategy of multisample parallel genome sequencing reported in our previous study, 61 homozygous variants were detected in C416; only the mutations located in chromosome III and 0 were considered for further screening (Table 2). CUFF.40834 showed a thymine $\rightarrow$ cytosine single base substitution in the exon, resulting in a change in amino acid from leucine to serine and was regarded as the candidate gene. BLAST analysis of the CUFF.40834 amino acid sequence on the NCBI website revealed that it exhibited high identity to ETR1 in Glycine max, Medicago truncatula and Arabidopsis thaliana (Fig. 3B), and physiological assays demonstrated that $\mathrm{C} 416$ was insensitive to ACC (Fig. 4). Transcriptome profiling of petals at different developmental stages in the WT and $C 416$ revealed that ethylene signaling transduction was inhibited in C416, which might be responsible for the delayed flower senescence in C416 (Fig. 6). In Arabidopsis thali$a n a$, there are five membrane-bound ethylene receptor isoforms, including ETR1, ERS1 (ethylene response sensor 1), EIN4 (ethylene insensitive 4), ETR2, and ERS2, which regulate the activity of the downstream mitogen-activated protein kinase kinase kinase, CTR1. They function as negative regulators of ethylene signaling [9]. Dominant mutations in ETR1, ETR2, and EIN4 caused ethylene insensitivity in Arabidopsis thaliana. Among these receptors, ETR1 plays a predominant role in ethylene perception. Ethylene insensitivity is conferred by dominant mutations in the ETR1 gene [44-48]. It has also been reported that the Lotus japonicus line transformed with the Arabidopsis thaliana ETR1-1 gene delayed petal senescence and showed ethylene insensitivity [49]. However, unlike the mutant line produced by exogenous DNA introduction, the phenotype of $C 416$ was caused by a mutation in the endogenous ETR1 gene. At the transcriptome level, from S1 to S2, EBF1, which negatively regulates the ethylene signaling pathway by mediating the degradation of EIN3/EIL [50, 51], was significantly upregulated in C416, whereas no obvious change was detected in the WT; EIN3, which is a positive regulator of ethylene response, showed no significant change in
C416, but was upregulated in the WT. In C416-S2, ERF transcription factors, including WIN1, ERF010, PAP2-3, and TINY, exhibited lower expression levels compared to those in WT-S2. Three DEGs (CUFF.55905, CUFF.8415, and CUFF.8416) involved in nodulation were detected by RNA-seq in WT vs. C416, all of which were upregulated in C416. As ethylene has been demonstrated to play a special role in regulating symbiotic nitrogen-fixation and nodulation organogenesis in legumes [18-20], C416 might also be a useful tool to study the effect of ethylene on nodulation by using mutants of endogenous genes in Lotus japonicus, rather than mutant lines through introduction of exogenous genes by transgenic techniques.

Petals in flowering plants senesce after pollination or according to the time following flower opening, regardless of whether they are pollinated or not. In some species, pollination dramatically shortens floral life span, as seen in orchid flowers, petunias, tobacco and carnations, senescence is triggered by ethylene following contact between pollen and the stigma surface [52-58]. When considering the different developmental stages, the number of DEGs in S1 vs. S2 was much higher than that in S2 vs. S3. Meanwhile, WT-S2 vs. C416-S2 had more DEGs than those of WT-S1 vs. C416-S1 (Fig. 5B). These results indicate that pollination-related processes might stimulate flower senescence in Lotus japonicus.

Flower senescence is delayed but not completely suppressed in C416, indicating that besides ethylene, other phytohormones might be also involved in the regulation of flower senescence in C416. Generally speaking, focused on flower senescence, ethylene and ABA promote senescence, whereas cytokinins and GA inhibit this process; auxin exhibits dual effects that can both accelerate or delay plant senescence. Compared to the above hormones, SA, JA and BR were also reported to influence petal senescence, however, the effects of SA, JA and BR on petal senescence are largely undefined [21, 59-62].

GA-insensitive dwarf 2 protein (GID2) is essential for GA-mediated DELLA protein degradation [63]. Here, GID2 was significantly upregulated from WT-S1 to WT-S2, whereas no obvious change was detected in C416-S1 to C416-S2. Endogenous cytokinin levels decline during the leaf aging process, and exogenous application can delay leaf and petal senescence $[64,65]$. In C416-S2, ARR11 (Arabidopsis response regulator 11), which is involved in the cytokinin-activated signaling pathway, was upregulated compared to that in WT-S2; ARR9 and ARR 12 were significantly upregulated from C416-S1 to C416-S2, whereas no obvious change was detected in WT-S1 vs. WT-S2. AHP4, which was inferred to play a negative role in several cytokinin responses [66] 
exhibited no significant changes in C416-S1 vs. C416-S2 when it was upregulated from WT-S1 to WT-S2.

$\mathrm{SA}$ is considered as promoter of leaf senescence, however, it has been found that exogenous application of SA increased the vase life of lisianthus, gladiolus and chrysanthemums [67-69]. In addition, RNA sequencing and microarray analysis showed that SA biosynthesis related factors were downregulated in opening stage while upregulated in senescent stage [70]. The SA response factor TGA3 exhibited no obvious change from C416-S1 to C416-S2, whereas it was significantly upregulated in WT; furthermore, its expression level in C416-S2 was lower than that in WT-S2. Exogenous methyl jasmonate application accelerated petal senescence in Rosa hybrida, Petunia hybrid, and Dendrobium spp. by increasing ACC levels to elevate ethylene production [71, 72]. However, JA treatment delayed tepal senescence of Iris flowers by 2 days [73]. In C416-S2, $J A R 1$, which encodes jasmonic acid amido synthetase, was downregulated compared to that in the WT-S2. MYC2, which positively regulates a series of JA-dependent responses [74], was significantly downregulated from C416-S1 to C416-S2, whereas no obvious changes were observed in WT-S1 vs. WT-S2. In Arabidopsis, BR receptor mutant bril shows a premature leaf senescence phenotype [75]. Exogenous BR delayed senescence in Carica papaya L. leaves [62]. During rose petal senescence, the accumulation of putative BR SIGNALING KINASE (BSK) proteins were increased [76]. Here, the brassinosteroid insensitive 1-associated receptor kinase 1 (BAK1) was significantly upregulated from C416-S1 to C416-S2, whereas no obvious change was detected in WT-S1 vs. WT-S2.

Auxin exhibits dual effects that can accelerate or delay plant senescence. Several studies have demonstrated that auxin functions as a negative regulator of senescence, as exogenous application to the detached leaves of Arabidopsis thaliana resulted in the downregulation of SAG12 [77]. The ORESARA14 (encoding ARF2) knockout mutant line, as well as the YUCCA6 (auxin biosynthetic gene) overexpression line showed delayed leaf senescence in Arabidopsis thaliana [78, 79]. In contrast, auxin can also promote leaf senescence by upregulating $S A U R$ , which is a positive regulator of the senescence process $[80,81]$; GH3 was upregulated during dark-induced senescence in Arabidopsis thaliana [78]. In the present study, SAUR-like auxin responsive protein and GH3.6 were significantly upregulated from WT-S1 to WT-S2, whereas no obvious changes were detected in C416-S1 vs. C416-S2. ARF, IAA13, and IAA19 were significantly upregulated from C416-S1 to C416-S2, and no obvious changes were detected in WT-S1 vs. WT-S2. Meanwhile,
ARF1, ARG7, X10A and auxin-induced protein encoding gene $15 \mathrm{~A}$ involved in the auxin metabolic pathway were upregulated in C416-S2 compared to those in the WT-S2. This indicated that auxin also had a dual effect on flower senescence in Lotus japonicus.

$\mathrm{ABA}$ acts as a positive regulator of senescence. In ethylene-insensitive plants, $\mathrm{ABA}$ has been reported to play a predominant roles in flower senescence [82]. PP2C is a negative regulator of abscisic acid signaling by inhibiting the activity of SnRK2 and negatively regulates Arabidopsis leaf senescence [83]. There were no significant changes in C416-S1 vs. C416-S2, when significantly upregulated from WT-S1 to WT-S2. In C416-S2, the serine/threonine-protein kinase SRK2I, which is a core factor of the ABA-activated signaling pathway, was upregulated compared to that in WT-S2. Thus, ABA might be activated to promote flower senescence when the regulatory effects of ethylene are defective in C416.

\section{Conclusions}

Mutation breeding by heavy-ion beam irradiation has the potential to improve flower longevity in legume plants. C416, which displayed delayed flower senescence, was induced by carbon-ion beam irradiation. This study aimed to identify the candidate genes responsible for the delayed senescence of C416. By association analysis of multi-omics and genetic mapping, CUFF.40834, which encodes ETR1, was identified as the most probable candidate. C416 is insensitive to exogenous ACC application. This is the first reported mutant caused by endogenous ethylene-related genes in Lotus japonicus, rather than through the introduction of exogenous genes by transgenic techniques. Based on the present results and discussion, we provided a schematic of expression profile of plant hormone signaling transduction genes in flower senescence delayed mutant C416 (Fig. 7). In brief, the ethylene, JA, and SA signaling pathways were negatively regulated in C416, whereas the BR and cytokinin signaling pathways were positively regulated, and auxin exhibited dual effects on flower senescence in Lotus japonicus. The ABA signaling pathway was positively regulated in $C 416$, and $A B A$ might be the major phytohormone factor that promotes senescence when the ethylene signaling pathway is blocked in Lotus japonicus. This study is informative for elucidation of the molecular mechanism of delayed flower senescence in C416, lays a foundation for candidate flower senescence gene identification in Lotus japonicus, and provides another perspective for the improvement of flower longevity in legume plants by heavy-ion beam. 


\section{Methods}

Carbon-ion beam irradiation and plant growth conditions The seeds of wild-type (WT) Lotus japonicus (ecotype: Miyakojima MG-20 and Gifu B-129) were bought from Frontier Science Research Center, University of Miyazaki, Japan. The dry seeds of laboratory wild-type (WT) Lotus japonicus (ecotype: Miyakojima MG-20) were exposed to ${ }^{12} \mathrm{C}^{6+}$ ions at $400 \mathrm{~Gy}$ (energy, $80.55 \mathrm{MeV} /$ nucleon; average LET within samples, $31 \mathrm{keV} / \mu \mathrm{m}$ ) generated by the HIRFL at the Institute of Modern Physics, Chinese Academy of Sciences. The flower senescence-delayed mutant line C416 of Lotus japonicus (background Miyakojima MG-20 ecotype) was isolated from the $\mathrm{M}_{2}$ population. Mutation screening methods have been described in our previous study [35]. Plants were grown under greenhouse conditions: $22^{\circ} \mathrm{C}$ with a photoperiod of $18 \mathrm{~h}$-light/6h-dark, with a light intensity of $6000 \mathrm{~lx}$.

\section{Whole genome re-sequencing and mutation verification}

Young leaves of the WT line and six $\mathrm{M}_{4}$ lines (C16, yellow leaves; C416, delayed flower senescence; C83, C221, C328, and C434, inconspicuous phenotypes) derived from carbon-ion beam were used for genomic DNA extraction by cetyltrimethylammonium bromide (CTAB) method. The extracted DNA was sequenced using IIIumina HiSeqTM 2500 system (Illumina, Inc.; San Diego, CA, USA) at the Biomarker Technologies Company (Beijing, China). Bioinformatics analysis was performed as previously described [31, 41]. In short, the clean data were mapped to the reference genome of Lotus_r3.0 (ftp://ftp.kazusa.or.jp/pub/lotus/lotus_r3.0/) by using the Burrows-Wheeler Alignment v.0.7.15 tool [84] and SAMtools v.1.3.1 [85]. Qualimap v.2.2.1 was used to examine the sequencing alignment data, and the overall view of the data is shown in supplementary Table S2. Variant calling was carried out using VarScan 2 (v.3.9) algorithms [86]. The variants that were shared between two or among more sequenced lines were ruled out because they may preexist in the primordial WT lines. The variants with allele frequencies above 0.75 were called homozygous mutations, whereas all others were called heterozygous. Here, we only considered homozygous mutations in C416 genome as it is a stable mutant. After verified by IGV, the remaining variants were annotated using the SnpEff toolbox to evaluate the effects of mutations on gene functions, based on the gene structure predictions in the annotations of Lotus_r3.0 (ftp://ftp.kazusa. or.jp/pub/lotus/lotus_r3.0/Lj3.0_gene_models.gff3.gz). Meanwhile, several randomly selected variants were sequenced by sanger sequencing. Primers were designed using Primer3 (ver. 0.4.0; http://bioinfo.ut.ee/primer3-0.
4.0/), and the sequences of all primers are shown in supplementary Table S3.

\section{Genetic rough mapping}

C416 plants were crossed with another Lotus japonicus wild type (WT) Gifu B-129. DNA was isolated from $F_{2}$ plants that displayed homozygous recessive phenotypes using the CTAB method. Several simple sequence repeat (SSR) markers (http://www.kazusa.or.jp/lotus/markerdb_ index.html) were selected to determine the approximate chromosomal position of the mutation through polyacrylamide gel electrophoresis. Primer information for these markers is shown in supplementary Table S4.

\section{RNA isolation and sequencing}

For the flower senescence-delayed mutant line C416, petals were collected during three periods: 2 days before pollination (Stage 1, S1), 2 days after pollination (Stage 2, S2) and 8 days after pollination (Stage 3, S3). WT group included only the first two periods ( $\mathrm{S} 1$ and $\mathrm{S} 2$ ) as the petals had already faded in S3. Each group contained at least three biological replicates. Total RNA was extracted using the RNAprep Pure Plant Kit according to the manufacturer's protocol (TIANGEN, China). RNA quality was assessed using NanoPhotometer spectrophotometer (IMPLEN, CA, USA), Qubit RNA Assay Kit in Qubit 2.0 Fluorometer (Life Technologies, CA, USA), and RNA Nano 6000 Assay Kit of the Agilent Bioanalyzer 2100 system (Agilent Technologies, CA, USA). Samples were sent to the Biomarker Technologies Company (Beijing, China) for library preparation and sequencing on an Illumina Hiseq 4000 platform. Adapter sequences and low-quality sequence reads were removed from the datasets. Clean reads were mapped to the reference genome sequence (Table S5). Differential expression analysis of two conditions/groups was performed using the DESeq $R$ package. Differential gene expression was determined by the standard of $F C \geq 2$, with a false discovery rate of $p \leq 0.01$. Eighteen genes were selected randomly to validate the expression profiles of RNA-seq by real-time quantitative reverse transcription PCR (RT-qPCR), for which the primer information is shown in supplementary Table S6.

\section{Real-time quantitative reverse transcription PCR}

Primers were designed using the Primer 3 program (http://primer3.ut.ee/\#userconsent\#), and synthesized by Sangon Biotech (China). cDNA was synthesized using the Transcriptor First Strand cDNA Synthesis Kit (Roche, Germany). RT-qPCR was performed using Rotor-Gene Q (Qiagen, Germany) following the FastStart Essential DNA Green Master kit (Roche, Germany). The 
PCR cycles consisted of initial denaturation at $95^{\circ} \mathrm{C}$ for $10 \mathrm{~min}$, followed by 40 cycles of $95^{\circ} \mathrm{C}$ for $15 \mathrm{~s}$ and $60^{\circ} \mathrm{C}$ for $60 \mathrm{~s}$. The expression level of $\beta$-actin (Lj2g3v0916200, CUFF.35861.2) was used as an endogenous control for normalization.

\section{Bioinformatic analysis of protein}

Based on the amino acid sequence of target protein, online systems including SWISS-MODEL (https://swiss model.expasy.org/), Plant-mPLoc (http://www.csbio. sjtu.edu.cn/bioinf/plant-multi/), PredictProtein (https:// predictprotein.org/), and Expasy ProtScale (https://web. expasy.org/cgi-bin/protscale/protscale.pl/) were used to perform a protein 3D structure modeling, subcellular localization prediction, and physicochemical property analysis [87-89]. The amino acid sequence of target protein was also submitted to Basic Local Alignment Search Tool (BLAST) for sequence similarity calculating and phylogenetic analysis.

\section{Response to exogenous ACC treatment}

For the triple response assay, dry seeds were pretreated with abrasive paper, surface-sterilized with bleach for $15 \mathrm{~min}$, washed with sterile water five times, and then sown on 1/2 Murashige and Skoog (MS) medium plates containing $0,2,5,10$, and $50 \mu \mathrm{M}$ ACC. The medium plates were wrapped with aluminum foil, transferred to the growth room, and cultured in a vertical direction. The image of the seedlings was captured at 10th day after the transfer. The length of the hypocotyls was analyzed using ImageJ software. For the gene expression model assay involved in ethylene synthesis or signal transduction, seeds were sown on $1 / 2$ MS medium plates for 2 days, then transferred to a medium containing $5 \mu \mathrm{M}$ ACC and harvested at $0,2,4$, and $6 \mathrm{~h}$ after transfer. Detached flowers of different developmental stages were floated in liquid containing 0 and $100 \mu \mathrm{M} \mathrm{ACC}$, and the image was captured after 7 days.

\section{Statistical analysis}

Statistical significance of the results was examined using one-way ANOVA with a multiple comparison test, $t$-test or chi-squared test using SPSS statistics 17.0. Differences between samples were considered significant when the $p$-value was less than 0.05 .

\section{Abbreviations}

ACC: 1-Aminocyclopropane 1-carboxylic acid; ABA: Abscisic acid; BR: Brassinosteroid; CTAB: Cetyltrimethylammonium bromide; DEGs: Differential expression genes; DSBs: DNA double stranded breaks; HIRFL: Heavy lon Research Facility In Lanzhou; InDels: Insertions and deletions; JA: Jasmonic acid; LET: Linear energy transfer; MS: Murashige and Skoog; NGS: Next generation sequencing; RT-qPCR: Real-Time Quantitative reverse transcription Polymerase
Chain Reaction; RBE: Relative biological effectiveness; SA: Salicylic acid; SBSS: Single base substitutions; WT: Wild type.

\section{Supplementary Information}

The online version contains supplementary material available at https://doi. org/10.1186/s12870-021-03283-0.

Additional file 1: Fig. S1. The amplification pattern of genetic mapping markers. " $P$ " indicates the band pattern of the MG20 ecotype genomic DNA, "G" indicates the band pattern of the Gifu B-129 ecotype genomic DNA. 1-23 represent the individual plant that carrying homozygous recessive gene in the $F_{2}$ population.

Additional file 2: Fig. S2. Verification of a part of detected mutations by Sanger sequencing.

Additional file 3: Fig. S3. Verification of DNA sequence variation of candidate gene CUFF.40834.

Additional file 4: Fig. S4. Fold changes of 18 DEGs in RNA-Seq. Additional file 5: Fig. S5. Relative expressions of 18 DEGs tested by RT-qPCR.

Additional file 6: Table S1. Homozygous variants detected in C416. Additional file 7: Table S2. Whole genome re-sequencing data generated and mapping to the Lotus japonicus genome.

Additional file 8: Table S3. List of primers used for sanger sequencing. Additional file 9: Table S4. List of primers used for genetic mapping. Additional file 10: Table S5. RNA-sequencing data generated and mapping to the Lotus japonicus genome.

Additional file 11: Table S6. List of primers used for RT-qPCR.

\section{Acknowledgements}

We are very grateful to members of the Biophysics Group in Institute of Modern Physics, Chinese Academy of Sciences. We appreciate Dr. Wenlong Luo from Guangdong Academy of Agriculture Sciences for giving us valuable suggestions about the NGS data process. We appreciated Dr. Yaping Chen from Key Laboratory of Plant Resources Conservation and Sustainable Utilization, South China Botanical Garden, Chinese Academy of Sciences for giving us valuable suggestions and help about the rough mapping of C416.

\section{Authors' contributions}

LBZ coordinated and supervised the project, and corrected the manuscript. YD, SWL designed the experiments and wrote the manuscript. YD and SWL analyzed the next generation sequencing data, as well as the verification. JZ and ZF performed the genetic mapping of C416. XC, WBR and XL performed the physiological assay. YQ, LXY, ZZW, and WJL performed the irradiation, mutation screening and phenotype assay. $J L$ contributed to the bioinformatics analysis of CUFF.40834 protein and gave suggestion on phenotype assay. All authors were involved in the interpretation, reviewed and approved the final manuscript.

\section{Funding}

In this work, the experimental design and data analysis was supported by the Key-Area Research and Development Program of Guangdong Province (2018B020206002) and National Natural Science Foundation of China (No. 11705249). This study was also financially supported by the National Natural Science Foundation of China (No. 11705249; 11975285; U1632140), Youth Innovation Promotion Association of CAS (No. Y201974), Science and Technology Research Cooperation Project of Sichuan Provincial Institutes and Universities (18SYXHZ0014).

\section{Availability of data and materials}

Data of RNA-seq in this study is available in NCBI with accession number SRP115872. The whole-genome sequencing data in this study have been deposited in the Genome Sequence Archive (Genomics, Proteomics \& Bioinformatics 2017) in in National Genomics Data Center (Nucleic Acids Res 
2020), Beijing Institute of Genomics (China National Center for Bioinformation), Chinese Academy of Sciences, under accession number CRA002796 that are publicly accessible at https://bigd.big.ac.cn/gsa.

\section{Declarations}

\section{Ethics approval and consent to participate}

Not applicable.

\section{Consent for publication}

Not applicable.

\section{Competing interests}

The authors declare that they have no conflict of interest.

\begin{abstract}
Author details
${ }^{1}$ Biophysics Group, Biomedical Center, Institute of Modern Physics, Chinese Academy of Sciences, 730000 Lanzhou, People's Republic of China. ${ }^{2}$ University of Chinese Academy of Sciences, Beijing 100000, People's Republic of China. ${ }^{3}$ Guangdong Key Laboratory for New Technology Research of Vegetables, Vegetable Research Institute, Guangdong Academy of Agricultural Sciences, Guangzhou 510640, Guangdong, China. ${ }^{4}$ School of Life Science and Engineering, Lanzhou University of Technology, Lanzhou 730000, People's Republic of China. ${ }^{5}$ Kejin Innovation Institute of Heavy lon Beam Biological Industry, Baiyin 730900, People's Republic of China. ${ }^{6}$ Institute of Geographic Sciences and Natural Resources Research, Chinese Academy of Sciences, Beijing 100000, People's Republic of China.
\end{abstract}

Received: 14 April 2021 Accepted: 20 October 2021 Published online: 03 November 2021

\section{References}

1. Van Doorn WG, Woltering EJ. Physiology and molecular biology of petal senescence. J Exp Bot. 2008;59(3):453-80. https://doi.org/10.1093/jxb/ erm356.

2. Khan NA, Khan MIR, Ferrante A, Poor P. Editorial: ethylene: a key regulatory molecule in plants. Front Plant Sci. 2017;8. https://doi.org/10.3389/fpls. 2017.01782

3. Iqbal N, Khan NA, Ferrante A, Trivellini A, Francini A, Khan MIR. Ethylene role in plant growth, development and senescence: interaction with other phytohormones. Front Plant Sci. 2017;8. https://doi.org/10.3389/ fpls.2017.00475.

4. Shibuya K. Molecular aspects of flower senescence and strategies to improve flower longevity. Breed Sci. 2018;68(1, SI):99-108. https://doi. org/10.1270/jsbbs.17081.

5. Ma N, Ma C, Yang L, Shahid M, Wang C, Gao J. Petal senescence: a hormone view. J Exp Bot. 2018;69(4):719-32. https://doi.org/10.1093/jxb/ ery009.

6. Yin J, Chang X, Kasuga T, Bui M, Reid MS, Jiang C-Z. A basic helix-loophelix transcription factor, $\mathrm{PhFBH4}$, regulates flower senescence by modulating ethylene biosynthesis pathway in petunia. Horticult Res. 2015;2. https://doi.org/10.1038/hortres.2015.59.

7. In B-C, Ha STT, Lee YS, Lim JH. Relationships between the longevity, water relations, ethylene sensitivity, and gene expression of cut roses. Postharvest Biol Technol. 2017;131:74-83. https://doi.org/10.1016/j.postharvbio. 2017.05.003.

8. Ceusters J, Van de Poel B. Ethylene exerts species-specific and agedependent control of photosynthesis. Plant Physiol. 2018;176(4):2601-12. https://doi.org/10.1104/pp.17.01706.

9. Binder BM. Ethylene signaling in plants. J Biol Chem. 2020;295(22):771025. https://doi.org/10.1074/jbc.REV120.010854.

10. Shibuya K, Barry KG, Ciardi JA, Loucas HM, Underwood BA, Nourizadeh S, et al. The central role of PhEIN2 in ethylene responses throughout plant development in petunia. Plant Physiol. 2004;136(2):2900-12. https://doi. org/10.1104/pp.104.046979.

11. Sriskandarajah S, Mibus H, Serek M. Transgenic Campanula carpatica plants with reduced ethylene sensitivity. Plant Cell Rep. 2007;26(6):80513. https://doi.org/10.1007/s00299-006-0291-6.
12. Tanase K, Aida R, Yamaguchi H, Tanikawa N, Nagata M, Onozaki T, et al. Heterologous expression of a mutated carnation ethylene receptor gene, dc-ETR1nr, suppresses petal abscission and autocatalytic ethylene production in transgenic Torenia fournieri Lind. J Japanese Soc Horticult Sci. 2011;80(1):113-20. https://doi.org/10.2503/jjshs1.80.113.

13. Cervantes $E$, Rodríguez A, Nicolás G. Ethylene regulates the expression of a cysteine proteinase gene during germination of chickpea (Cicer arietinum L.). Plant Mol Biol. 1994;25(2):207-15. https://doi.org/10.1007/ BF00023238.

14. Jones ML, Larsen PB, Woodson WR. Ethylene-regulated expression of a carnation cysteine proteinase during flower petal senescence. Plant Mol Biol. 1995;28(3):505-12. https://doi.org/10.1007/BF00020397.

15. Wan L, Xia Q, Qiu X, Selvaraj G. Early stages of seed development in Brassica napus: a seed coat-specific cysteine proteinase associated with programmed cell death of the inner integument. Plant J. 2002;30(1):1-10. https://doi.org/10.1046/j.1365-313X.2002.01262.x.

16. Matarasso N, Schuster S, Avni A. A novel plant cysteine protease has a dual function as a regulator of 1-Aminocyclopropane-1-carboxylic acid synthase gene expression. Plant Cell. 2005;17(4):1205-16. https://doi.org/ 10.1105/tpc.105.030775.

17. Zhang D, Liu D, Lv X, Wang Y, Xun Z, Liu Z, et al. The cysteine protease CEP1, a key executor involved in Tapetal programmed cell death, regulates pollen development in Arabidopsis. Plant Cell. 2014;26(7):2939-61 https://doi.org/10.1105/tpc.114.127282.

18. Oldroyd GED, Engstrom EM, Long SR. Ethylene inhibits the nod factor signal transduction pathway of Medicago truncatula. Plant Cell. 2001;13(8):1835-49. https://doi.org/10.1105/tpc.13.8.1835.

19. Nukui N, Ezura H, Yuhashi Kl, Yasuta T, Minamisawa K. Effects of ethylene precursor and inhibitors for ethylene biosynthesis and perception on nodulation in Lotus japonicus and Macroptilium atropurpureum. Plant Cell Physiol. 2000;41(7):893-7. https://doi.org/10.1093/pcp/pcd011.

20. Penmetsa RV, Cook DR. A legume ethylene-insensitive mutant hyperinfected by its rhizobial symbiont. Science. 1997;275(5299):527-30. https:// doi.org/10.1126/science.275.5299.527.

21. Tripathi SK, Tuteja N. Integrated signaling in flower senescence: an overview. Plant Signal Behav. 2007;2(6):437-45. https://doi.org/10.4161/psb.2. 6.4991.

22. Jorgensen R, Arathi HS. Floral longevity and autonomous selfing are altered by pollination and water availability in Collinsia heterophylla. Ann Bot. 2013;112(5):821-8. https://doi.org/10.1093/aob/mct146.

23. Arroyo MTK, Dudley LS, Jespersen G, Pacheco DA, Cavieres LA. Temperature-driven flower longevity in a high-alpine species of Oxalis influences reproductive assurance. New Phytol. 2013;200(4):1260-8. https://doi.org/ $10.1111 / \mathrm{nph} .12443$

24. Handberg K, Stougaard J. Lotus japonicus, an autogamous, diploid legume species for classical and molecular genetics. Plant J. 2005;2(4):48796. https://doi.org/10.1111/j.1365-313X.1992.00487.x.

25. Tanaka A, Shikazono N, Hase Y. Studies on biological effects of ion beams on lethality, molecular nature of mutation, mutation rate, and spectrum of mutation phenotype for mutation breeding in higher plants. J Radiat Res. 2010;51(3):223-33. https://doi.org/10.1269/jrr.09143.

26. Hase Y, Satoh K, Seito H, Oono Y. Genetic consequences of acute/chronic gamma and carbon ion irradiation of Arabidopsis thaliana. Front Plant Sci. 2020;11. https://doi.org/10.3389/fpls.2020.00336.

27. Yang G, Luo W, Zhang J, Yan X, Du Y, Zhou L, et al. Genome-wide comparisons of mutations induced by carbon-ion beam and gamma-rays irradiation in rice via resequencing multiple mutants. Front Plant Sci. 2019;10(1514). https://doi.org/10.3389/fpls.2019.01514.

28. Li F, Shimizu A, Nishio T, Tsutsumi N, Kato H. Comparison and characterization of mutations induced by gamma-ray and carbon-ion irradiation in rice (Oryza sativa L.) using whole-genome resequencing. G3-Genes Genomes Genet. 2019;9(11):3743-51. https://doi.org/10.1534/g3.119. 400555.

29. Ichida H, Morita R, Shirakawa Y, Hayashi Y, Abe T. Targeted exome sequencing of unselected heavy-ion beam-irradiated populations reveals less-biased mutation characteristics in the rice genome. Plant J. 2019;98(2):301-14. https://doi.org/10.1111/tpj.14213.

30. Hase Y, Satoh K, Kitamura S, Oono Y. Physiological status of plant tissue affects the frequency and types of mutations induced by carbon-ion irradiation in Arabidopsis. Sci Rep. 2018;8(1). https://doi.org/10.1038/ S41598-018-19278-1. 
31. Du Y, Luo S, Yu L, Cui T, Chen X, Yang J, et al. Strategies for identification of mutations induced by carbon-ion beam irradiation in Arabidopsis thaliana by whole genome re-sequencing. Mutat Res. 2018;807:21-30. https://doi.org/10.1016/j.mrfmmm.2017.12.001.

32. Kazama Y, Ishii K, Hirano T, Wakana T, Yamada M, Ohbu S, et al. Different mutational function of low- and high-linear energy transfer heavy-ion irradiation demonstrated by whole-genome resequencing of Arabidopsis mutants. Plant J. 2017;92(6):1020-30. https://doi.org/10.1111/tpj.13738.

33. Cui T, Luo S, Du Y, Yu L, Yang J, Li W, et al. Research of photosynthesis and genomewide resequencing on a yellow-leaf Lotus japonicus mutant induced by carbon ion beam irradiation. Grassl Sci. 2019;65(1):41-8. https://doi.org/10.1111/grs.12216.

34. Yu LX, Li WJ, Du Y, Chen G, Luo SW, Liu RY, et al. Flower color mutants induced by carbon ion beam irradiation of geranium (Pelargonium $x$ hortorum, Bailey). Nucl Sci Tech. 2016;27(112). https://doi.org/10.1007/ S41365-016-0117-3.

35. Luo S, Zhou L, Li W, Du Y, Yu L, Feng H, et al. Mutagenic effects of carbon ion beam irradiations on dry Lotus japonicus seeds. Nucl Instrum Methods Phys Res, Sect B. 2016;383:123-8. https://doi.org/10.1016/j.nimb. 2016.06.021.

36. Du Y, Li WJ, Yu LX, Chen G, Liu QF, Luo SW, et al. Mutagenic effects of carbon-ion irradiation on dry Arabidopsis thaliana seeds. Mutat Res. 2014;759(1):28-36. https://doi.org/10.1016/j.mrgentox.2013.07.018.

37. He JY, Lu D, Yu LX, Li WJ. Pigment analysis of a color-leaf mutant in wandering Jew (Tradescantia fluminensis) irradiated by carbon ions. Nucl Sci Tech. 2011;22(2):77-83.

38. Yu Z, Zhang T, Zhu Y. Whole-genome re-sequencing and transcriptome reveal cadmium tolerance related genes and pathways in Chlamydomonas reinhardtii. Ecotox Environ Safe. 2020;191. https://doi.org/10. 1016/j.ecoenv.2020.110231

39. Yuan $Y$, Yang $Y$, Shen $Y$, Yu K, Wang $L$, Ren $R$, et al. Mapping and functional analysis of candidate genes involved in resistance to soybean (Glycine max) mosaic virus strain SC3. Plant Breed. 2020;139(3):618-25. https://doi. org/10.1111/pbr.12799.

40. Yang BZ, Zhou SD, Ou LJ, Liu F, Yang LY, Zheng JY, et al. A novel singlebase mutation in CaBRI1 confers dwarf phenotype and brassinosteroid accumulation in pepper. Mol Gen Genomics. 2020;295(2):343-56. https:// doi.org/10.1007/s00438-019-01626-z.

41. Du Y, Luo S, Li X, Yang J, Cui T, Li W, et al. Identification of substitutions and small insertion-deletions induced by carbon-ion beam irradiation in Arabidopsis thaliana. Front Plant Sci. 2017;8(1851). https://doi.org/10. 3389/fpls.2017.01851.

42. Rogers HJ. Programmed cell death in floral organs: how and why do flowers die? Ann Bot. 2006:97(3):309-15. https://doi.org/10.1093/aob/mcj051.

43. Sato S, Nakamura Y, Kaneko T, Asamizu E, Kato T, Nakao M, et al. Genome structure of the legume, Lotus japonicus. DNA Res. 2008;15(4):227-39. https://doi.org/10.1093/dnares/dsn008.

44. Bleecker AB, Estelle MA, Somerville C, Kende H. Insensitivity to ethylene conferred by a dominant mutation in Arabidopsis thaliana. Science. 1988;241 (4869):1086-9. https://doi.org/10.1126/science.241.4869.1086.

45. Chang C, Kwok SF, Bleecker AB, Meyerowitz EM. Arabidopsis ethyleneresponse gene ETR1 - similarity of product to 2-component regulators. Science. 1993;262(5133):539-44. https://doi.org/10.1126/science. 8211181.

46. Schaller GE, Bleecker AB. Ethylene-binding sites generated in yeast expressing the Arabidopsis ETR1 gene. Science. 1995;270(5243):1809-11. https://doi.org/10.1126/science.270.5243.1809.

47. Hall $A E$, Chen $Q H G$, Findell $J L$, Schaller GE, Bleecker AB. The relationship between ethylene binding and dominant insensitivity conferred by mutant forms of the ETR1 ethylene receptor. Plant Physiol. 1999;121(1):291-9. https://doi.org/10.1104/pp.121.1.291.

48. Wang W, Esch JJ, Shiu S-H, Agula H, Binder BM, Chang C, et al. Identification of important regions for ethylene binding and signaling in the transmembrane domain of the ETR1 ethylene receptor of Arabidopsis. Plant Cell. 2006;18(12):3429-42. https://doi.org/10.1105/tpc.106.044537.

49. Lohar D, Stiller J, Kam J, Stacey G, Gresshoff PM. Ethylene insensitivity conferred by a mutated Arabidopsis ethylene receptor gene alters nodulation in transgenic Lotus japonicus. Ann Bot. 2009;104(2):277-85. https:// doi.org/10.1093/aob/mcp132.
50. Hyten DL, Cannon SB, Song Q, Weeks N, Fickus EW, Shoemaker RC, et al. High-throughput SNP discovery through deep resequencing of a reduced representation library to anchor and orient scaffolds in the soybean whole genome sequence. BMC Genomics. 2010;11. https://doi. org/10.1186/1471-2164-11-38.

51. Guo XK, Zhang Y, Tu Y, Wang YZ, Cheng WJ, Yang YW. Overexpression of an EIN3-binding F-box protein2-like gene caused elongated fruit shape and delayed fruit development and ripening in tomato. Plant Sci. 2018;272:131-41. https://doi.org/10.1016/j.plantsci.2018.04.016.

52. Jones ML, Woodson WR. Pollination-induced ethylene in carnation - role of stylar ethylene in corolla senescence. Plant Physiol. 1997;115(1):205-12. https://doi.org/10.1104/pp.115.1.205.

53. Xu Y, Hanson MR. Programmed cell death during pollination-induced petal senescence in petunia. Plant Physiol. 2000;122(4):1323-33. https:// doi.org/10.1104/pp.122.4.1323.

54. Holden MJ, Marty JA, Singh-Cundy A. Pollination-induced ethylene promotes the early phase of pollen tube growth in Petunia inflata. J Plant Physiol. 2003;160(3):261-9. https://doi.org/10.1078/0176-1617-00929.

55. Attri LK, Nayyar H, Bhanwra RK, Vij SP. Pollination-induced floral senescence in orchids: status of oxidative stress. Russ J Plant Physiol. 2008;55(6):821-8. https://doi.org/10.1134/s1021443708060125.

56. Bai S, Willard B, Chapin L, Kinter MT, Francis DM, Stead AD, et al. Proteomic analysis of pollination-induced corolla senescence in petunia. Exp Bot. 2010;61(4):1089-109. https://doi.org/10.1093/jxb/erp373.

57. Sanchez AM, Mariani C. Expression of the ACC synthase and ACC oxidase coding genes after self-pollination and incongruous pollination of tobacco pistils. Plant Mol Biol. 2002;48(4):351-9. https://doi.org/10. 1023/a:1014087914652.

58. Bhattacharya S, Baldwin IT. The post-pollination ethylene burst and the continuation of floral advertisement are harbingers of non-random mate selection in Nicotiana attenuata. Plant J. 2012;71(4):587-601. https://doi. org/10.1111/j.1365-313X.2012.05011.x

59. Wojciechowska N, Sobieszczuk-Nowicka E, Bagniewska-Zadworna A Plant organ senescence - regulation by manifold pathways. Plant Biol. 2018;20(2):167-81. https://doi.org/10.1111/plb.12672.

60. Ahmad S, Guo Y. Signal transduction in leaf senescence: Progress and perspective. Plants-Basel. 2019;8(10):405. https://doi.org/10.3390/plant s8100405.

61. Chen L, Xiang S, Chen Y, Li D, Yu D. Arabidopsis WRKY45 interacts with the DELLA protein RGL1 to positively regulate age-triggered leaf senescence. Mol Plant. 2017;10(9):1174-89. https://doi.org/10.1016/j.molp.2017.07.008.

62. de Assis-Gomes MM, Pinheiro DT, Bressan-Smith R, Campostrini E. Exogenous brassinosteroid application delays senescence and promotes hyponasty in Carica papaya L. leaves. Theor Exp Plant Physiol. 2018;30(3):193-201. https://doi.org/10.1007/s40626-018-0114-5.

63. Gomi K, Sasaki A, Itoh H, Ueguchi-Tanaka M, Ashikari M, Kitano H, et al. GID2, an F-box subunit of the SCF E3 complex, specifically interacts with phosphorylated SLR1 protein and regulates the gibberellin-dependent degradation of SLR1 in rice. Plant J. 2004;37(4):626-34. https://doi.org/10. 1111/j.1365-313X.2003.01990.x.

64. Hwang I, Sheen J, Mueller B. Cytokinin signaling networks. Annu Rev Plant Biol. 2012;63:353-80. https://doi.org/10.1146/annurev-arpla nt-042811-105503.

65. Khaskheli AJ, Ahmed W, Ma C, Zhang S, Liu YY, Li YQ, et al. Rherf113 functions in ethylene-induced petal senescence by modulating cytokinin content in rose. Plant Cell Physiol. 2018;59(12):2442-51. https://doi.org/ 10.1093/pcp/pcy162.

66. Hutchison CE, Li J, Argueso C, Gonzalez M, Lee E, Lewis MW, et al. The Arabidopsis histidine phosphotransfer proteins are redundant positive regulators of cytokinin signaling. Plant Cell. 2006;18(11):3073-87. https:// doi.org/10.1105/tpc.106.045674.

67. Bahrami SN, Zakizadeh H, Hamidoghli Y, Ghasemnezhad M. Salicylic acid retards petal senescence in cut lisianthus (Eustoma grandiflorum 'Miarichi grand White') flowers. Hortic Environ Biotechnol. 2013;54(6):51923. https://doi.org/10.1007/s13580-013-1058-y.

68. Ezhilmathi K, Singh VP, Arora A, Sairam RK. Effect of 5-sulfosalicylic acid on antioxidant activity in relation to vase life of Gladiolus cut flowers. Plant Growth Regul. 2007;51(2):99. https://doi.org/10.1007/s10725-006-9142-2. 
69. Mansouri H. Salicylic acid and sodium nitroprusside improve postharvest life of chrysanthemums. Sci Hortic. 2012;145:29-33. https://doi.org/10. 1016/j.scienta.2012.07.016.

70. Yang C-P, Xia Z-Q, Hu J, Zhuang Y-F, Pan Y-W, Liu J-P. Transcriptome analysis of Oncidium petals provides new insights into the initiation of petal senescence. J Horticult Sci Biotechnol. 2019;94(1):12-23. https://doi.org/ 10.1080/14620316.2018.1432297.

71. Zhang S, Zhao QC, Zeng DX, Xu JH, Zhou HG, Wang FL, et al. RhMYB108, an R2R3-MYB transcription factor, is involved in ethylene- and JA-induced petal senescence in rose plants. Horticult Res. 2019;6(131). https://doi. org/10.1038/s41438-019-0221-8.

72. Porat R, Halevy AH. Enhancement of petunia and dendrobium flower senescence by jasmonic acid methyl-ester is via the promotion of ethylene production. Plant Growth Regul. 1993;13(3):297-301. https://doi.org/ 10.1007/bf00024851.

73. van Doorn WG, Çelikel FG, Pak C, Harkema H. Delay of iris flower senescence by cytokinins and jasmonates. Physiol Plant. 2013;148(1):105-20. https://doi.org/10.1111/j.1399-3054.2012.01690.x.

74. Chico JM, Chini A, Fonseca S, Solano R. JAZ repressors set the rhythm in jasmonate signaling. Curr Opin Plant Biol. 2008;11(5):486-94. https://doi. org/10.1016/j.pbi.2008.06.003.

75. Clouse SD, Sasse JM. BRASSINOSTEROIDS: essential regulators of plant growth and development. Annu Rev Plant Physiol Plant Mol Biol. 1998;49:427-51. https://doi.org/10.1146/annurev.arplant.49.1.427.

76. Lu J, Xu Y, Fan Y, Wang Y, Zhang G, Liang Y, et al. Proteome and Ubiquitome Changes during Rose Petal Senescence. Int J Mol Sci. 2019;20(24). https://doi.org/10.3390/ijms20246108.

77. Noh YS, Amasino RM. Identification of a promoter region responsible for the senescence-specific expression of SAG12. Plant Mol Biol. 1999;41(2):181-94. https://doi.org/10.1023/a:1006342412688.

78. Kim JI, Murphy AS, Baek D, Lee S-W, Yun D-J, Bressan RA, et al. YUCCA6 over-expression demonstrates auxin function in delaying leaf senescence in Arabidopsis thaliana. J Exp Bot. 2011;62(11):3981-92. https://doi.org/ 10.1093/jxb/err094.

79. Lim PO, Lee IC, Kim J, Kim HJ, Ryu JS, Woo HR, et al. Auxin response factor 2 (ARF2) plays a major role in regulating auxin-mediated leaf longevity. J Exp Bot. 2010;61(5):1419-30. https://doi.org/10.1093/jxb/erq010.
80. Hou K, Wu W, Gan S-S. SAUR36, a SMALL AUXIN UP RNA gene, is involved in the promotion of leaf senescence in Arabidopsis. Plant Physiol. 2013;161(2):1002-9. https://doi.org/10.1104/pp.112.212787.

81. Wen Z, Mei Y, Zhou J, Cui Y, Wang D, Wang NN. SAUR49 can positively regulate leaf senescence by suppressing SSPP in Arabidopsis. Plant Cell Physiol. 2019;61(3):644-58. https://doi.org/10.1093/pcp/pcz231.

82. Panavas T, Walker EL, Rubinstein B. Possible involvement of abscisic acid in senescence of daylily petals. J Exp Bot. 1998;49(329):1987-97. https:// doi.org/10.1093/jxb/49.329.1987.

83. Gosti F, Beaudoin N, Serizet C, Webb AA, Vartanian N, Giraudat J. ABI1 protein phosphatase $2 \mathrm{C}$ is a negative regulator of abscisic acid signaling. Plant Cell. 1999;11(10):1897-910. https://doi.org/10.1105/tpc.11.10.1897.

84. Li H, Durbin R. Fast and accurate short read alignment with burrowswheeler transform. Bioinformatics. 2009;25(14):1754-60. https://doi.org/ 10.1093/bioinformatics/btp324.

85. Li H, Handsaker B, Wysoker A, Fennell T, Ruan J, Homer N, et al. The sequence alignment/map format and SAMtools. Bioinformatics. 2009:25(16):2078-9. https://doi.org/10.1093/bioinformatics/btp352.

86. Koboldt DC, Zhang QY, Larson DE, Shen D, McLellan MD, Lin L, et al. VarScan 2: somatic mutation and copy number alteration discovery in cancer by exome sequencing. Genome Res. 2012;22(3):568-76. https:// doi.org/10.1101/gr.129684.111.

87. Waterhouse A, Bertoni M, Bienert S, Studer G, Tauriello G, Gumienny R, et al. SWISS-MODEL: homology modelling of protein structures and complexes. Nucleic Acids Res. 2018;46(W1):W296-303. https://doi.org/10. 1093/nar/gky427.

88. Chou K-C, Shen H-B. Plant-mPLoc: A Top-Down Strategy to Augment the Power for Predicting Plant Protein Subcellular Localization. PLoS One. 2010;5(6). https://doi.org/10.1371/journal.pone.0011335.

89. Bernhofer M, Dallago C, Karl T, Satagopam V, Heinzinger M, Littmann M, et al. PredictProtein - predicting protein structure and function for 29 years. Nucleic Acids Res. 2021. https://doi.org/10.1093/nar/gkab354.

\section{Publisher's Note}

Springer Nature remains neutral with regard to jurisdictional claims in published maps and institutional affiliations.
Ready to submit your research? Choose BMC and benefit from:

- fast, convenient online submission

- thorough peer review by experienced researchers in your field

- rapid publication on acceptance

- support for research data, including large and complex data types

- gold Open Access which fosters wider collaboration and increased citations

- maximum visibility for your research: over $100 \mathrm{M}$ website views per year

At BMC, research is always in progress.

Learn more biomedcentral.com/submissions 